Cole, J. S., N. L. Michel, R. B. Siegel, and N. Somilleda, Jr. 2019. Effects of off-highway vehicles on avian abundance and diversity in a designated vehicular recreation area. Avian Conservation and Ecology 14(2):9. https://doi.org/10.5751/ACE-01422-140209

Copyright (C) 2019 by the author(s). Published here under license by the Resilience Alliance.

Research Paper

\title{
Effects of off-highway vehicles on avian abundance and diversity in a designated vehicular recreation area
}

\author{
Jerry S. Cole ${ }^{1}$, Nicole L. Michel ${ }^{2}$, Rodney B. Siegel ${ }^{1}$ and Nicolas Somilleda Jr. ${ }^{3}$ \\ ${ }^{1}$ The Institute for Bird Populations, ${ }^{2}$ National Audubon Society, ${ }^{3}$ California State Parks, Off-Highway Motor Vehicle Recreation \\ Division, Hollister Hills - State Vehicular Recreation Area
}

\begin{abstract}
More people are engaging in recreation on public lands in the United States than ever before. However, increased recreation can be detrimental to wildlife species. Managers need to understand how recreational activities, such as driving motor vehicles through natural areas, can affect a range of species so that they can balance access to nature with preservation of wildlife communities. We assessed the effect of off-highway vehicle (OHV) use and OHV trail density on the abundance and diversity of bird species across Hollister Hills State Vehicle Recreation Area in California, USA. We collected data during three winter and two spring seasons spanning 2012 to 2014. We used a hierarchical community distance sampling model to compare bird community and species-level abundance for 30 species in spring and 18 species in winter and used raw counts of birds to compare Shannon diversity between OHV use and nonOHV use areas. Community-level bird abundance increased significantly with OHV trail density in both winter and spring and was significantly greater in $\mathrm{OHV}$ use areas than in nonOHV use areas during the winter, but not spring. Seven and eight species, in spring and winter respectively, were significantly more abundant with greater OHV trail cover, and none was significantly less abundant. OHV use had no significant effect on Shannon diversity. Thus, OHV recreation appears to have had nonnegative effects on abundance and no discernable effect on diversity of birds at Hollister Hills. Abundance is not always a good predictor of habitat quality, however, so further research is needed to understand the demographic consequences of OHV use on bird species.
\end{abstract}

\section{Effets des véhicules hors-route sur l'abondance et la diversité des populations aviaires dans une zone réservée aux loisirs motorisés}

RÉSUMÉ. Le nombre de personnes pratiquant des loisirs sur des terrains publics aux États-Unis est plus élevé que jamais. Toutefois, cette augmentation des loisirs risque de nuire à certaines espèces sauvages. Les responsables doivent comprendre l'influence que peuvent avoir des activités de loisirs, telles que la conduite de véhicules à moteur dans des zones naturelles, sur différentes espèces, afin de trouver un juste équilibre entre l'accès à la nature et la protection des populations animales. Nous avons évalué les effets de l'utilisation de véhicules hors route (VHR) et de la densité de pistes pour VHR sur l'abondance et la diversité des espèces d'oiseaux dans la zone de loisirs d'état pour véhicules de Hollister Hills, en Californie. Nous avons collecté des données au cours de trois hivers et deux printemps de 2012 à 2014. Nous avons utilisé un modèle hiérarchisé d'échantillonnage de distance entre les communautés afin de comparer la population aviaire et l'abondance au niveau des espèces pour 30 espèces au printemps et 18 espèces en hiver. Nous avons utilisé le nombre brut d'oiseaux pour comparer la diversité de Shannon entre des zones d'utilisation et de non-utilisation de VHR. L'abondance d'oiseaux au niveau des communautés a nettement augmenté avec la densité des pistes pour VHR à la fois en hiver et au printemps et était nettement plus élevée dans les zones d'utilisation de VHR que dans les zones sans VHR pendant l'hiver, mais pas au printemps. Sept et huit espèces, au printemps et en hiver respectivement, étaient nettement plus abondantes dans les zones contenant davantage de pistes pour VHR, et aucune espèce n'y était moins abondante. L'utilisation de VHR n'avait pas d'effet significatif sur la diversité de Shannon. En conséquence, les loisirs utilisant des VHR semblent avoir eu des effets non-négatifs sur l'abondance et aucun effet perceptible sur la diversité des oiseaux à Hollister Hills. L'abondance n'est cependant pas toujours un bon indicateur de la qualité de l'habitat, de sorte que d'autres recherches sont nécessaires pour comprendre les conséquences démographiques de l'utilisation de VHR sur les espèces d'oiseaux.

Key Words: birds; California; distance sampling; disturbance; diversity; hierarchical modeling; off-highway vehicles

\section{INTRODUCTION}

Participation in outdoor recreation has increased markedly in recent years in the United States (Cordell 2012), presenting land managers with the challenge of balancing the potentially competing needs of facilitating outdoor recreation and preserving ecological communities (Madden 2004). One mode of outdoor recreation that may be particularly prone to creating such recreation/conservation trade-offs is motorized off-highway vehicle (OHV) use, “...including motorcycles, motorized dirt bikes, ATVs (all-terrain vehicles), snowmobiles, dune buggies, 4wheel-drive jeeps, sport-utility vehicles, and any other civilian vehicles capable of off-highway, terrestrial travel..." (Ouren et al. 2007: ix). The number of OHV users in the United States increased by a third in less than 10 years, climbing from 36 million in the early 2000s to 48.4 million later in the decade (Cordell 2012). Despite recent advances made in the field of "recreation ecology" 
(Monz et al. 2010) to study the effect of recreation on the surrounding environment, the potential threat that OHV use may pose to individual species and ecological communities within designated OHV parks remains little known.

Vehicular recreation has been shown to have a variety of deleterious effects on wildlife, including: triggering of defensive behaviors in birds when vehicles pass (e.g., Spaul and Heath 2017 , Felton et al. 2018), decreased avian nest survival (e.g., Steenhof et al. 2014, Borneman et al. 2016), and avoidance of OHV trails by mammals (e.g., Jones et al. 2017, Wisdom et al. 2018). However, most studies examining the effect of OHV use on birds have not been conducted in areas used and managed expressly for OHV recreation, but rather in multiple-use areas where OHV recreation is sometimes poorly regulated. In designated $\mathrm{OHV}$ use areas, wildlife response could either be more severe because of more intensive OHV use, or potentially less severe because of management actions aimed at limiting its effects (e.g., enforcement of trails-only riding or installation of trail fencing). In a designated $\mathrm{OHV}$ area in California, bird nests closer to OHV trails had greater desertion and abandonment rates, but nests built in shrubs closer to OHV trails had lower predation rates (although not significantly so) than those further away (Barton and Holmes 2007). Also in California, lower numbers of plants, arthropods, lizards, and mammals were present in areas heavily used by OHVs (Luckenbach and Bury 1983).

Most previous work assessing OHV effects on birds at both unregulated $\mathrm{OHV}$ use areas (with limited or no enforcement of riding rules and few or no defined trails) and well-regulated OHV use areas (with consistent enforcement of riding rules and many clearly defined trails) has helped quantify how motorized recreation affects a few individual species (e.g., Spaul and Heath 2017, Felton et al. 2018). However, at least one study has looked more broadly at effects on vertebrate species richness (Bury et al. 1977). Maintaining diverse and resilient communities of native species may be more important to many land managers than effects on any one particular species (Poiani et al. 2000).

Birds are ideally suited for community models because they are relatively easily identified to species and counted, and serve as useful indicators of ecosystem health (Canterbury et al. 2000). The recent development of hierarchical community modeling provides a means of determining the effect of factors such as management regime on a selected assemblage of species (Iknayan et al. 2014) and shows great promise for facilitating land management decisions likely to affect many species (e.g., Zipkin et al. 2010, Sauer et al. 2013, White et al. 2013). This approach differs from more traditional methods of working with count data, such as using raw counts uncorrected for imperfect detection to compare richness (e.g., Summers et al. 2011) or diversity (e.g., Perillo et al. 2017) between areas undergoing different management regimes, by accounting for imperfect detection. In $\mathrm{OHV}$ use areas, accounting for imperfect detection is likely to be especially important, where background noise may reduce detectability of birds, leading to undercounting. Multispecies abundance models allow for the modeling of a large number of species, including species typically excluded from single-species models due to small sample sizes (e.g., Sollmann et al. 2016), by sharing information via a random species effect informed by all species in the community (Zipkin et al. 2009). The distribution of this random effect for each parameter provides an estimation of a community response and propagates error from all species included in the model.

Resource managers faced with limited spatial and no withinseason temporal replication frequently choose to analyze count data using single species distance sampling, which restricts analyses to species with sufficient observations, typically at least 60-80 (Buckland et al. 1993), to fit models reliably. Other methods, apart from distance sampling alone, that account for imperfect detection, include $\mathrm{N}$-mixture modeling (Royle et al. 2004) or approaches that combine time-removal and distance sampling (e.g., Sólymos et al. 2013). Hierarchical community distance sampling models are particularly well suited for sparse data sets because estimates of effects for single species are assumed to come from a common distribution (community effect) that comprises all modeled species responses. Species with few observations, despite having little information from which to detect a signal, are informed by the community distribution. The community distance sampling modeling approach has been implemented infrequently (Goyert et al. 2016, Sollmann et al. 2016, Yamaura and Royle 2017, Farr et al. 2019), likely due to its recent development and Bayesian framework.

Here, we use a hierarchical community distance sampling model for seasonal point counts to compare bird assemblages occupying $\mathrm{OHV}$ use and nonuse areas of at Hollister Hills State Vehicle Recreation Area (SVRA) in California. We used data collected across three winters and two springs to build community models for each season, with species-level bird abundance as the response variable and OHV use (open or closed to OHV users), OHV trail cover per unit of area, and dominant habitat type (grassland, oak woodland, or chaparral) as the predictor variables. We also used uncorrected bird abundance to calculate and compare Shannon diversity, hereafter "diversity," between OHV use and nonOHV use areas. Uncorrected bird abundances were used for diversity calculations because we wanted to include the most representative assemblage possible (i.e., all detected species). We chose to not use community model derived abundances for diversity calculations because it would have limited the species to those abundant enough for reliable abundance estimation (i.e., not all detected species would be included). We predicted that mean bird abundance (average of abundance across each species) and abundance of individual bird species would be lower in OHV use areas and at points surrounded with greater OHV trail cover due to higher levels of noise and disturbance. We also predicted that the bird community would have a more negative response (in both mean abundance and diversity) to OHV use during the breeding season (spring) vs. the nonbreeding season (winter) because birds may be more likely to establish a territory further from disturbance during the breeding season to avoid subjecting their offspring to potentially high levels of noise and stress.

\section{METHODS}

\section{Study area}

Birds were surveyed throughout Hollister Hills SVRA (Fig. 1), an approximately 2,700-ha area administered by the Off-Highway Motor Vehicle Division of California State Parks. Hollister Hills SVRA is located in the Gabilan Mountain Range in central coastal California and includes both areas completely closed to 
vehicular recreation and others open to OHV use. The study area has a Mediterranean climate, with warm, dry summers and cool, wet winters, and vegetation consisting primarily of oak woodland, riparian forest, grassland, low chaparral, and high chaparral (California State Parks Off-highway Motor Vehicle Division Report 1978, unpublished manuscript). Oak woodland within the park is dominated by valley oak (Quercus lobata), blue oak (Quercus douglasii), and some California buckeye (Aesculus californica), whereas riparian forest is dominated by sycamore (Plantanus racemosa), willow (Salix spp.), alder (Alnus rhombifolia), and coast live oak (Quercus agrifolia). Grassland is dominated by wild oats (Avena fatua), bromes (Bromus spp.), needlegrass (Nassella spp.), bluegrass (Poa secunda), and a variety of wildflowers. Low chaparral is dominated by chamise (Adenostoma fasciculatum) and toyon (Heteromeles arbutifolia); and high chaparral by toyon, manzanita (Arctostaphylos spp.), scrub oak (Quercus dumosa), and interior live oak (Quercus wislizenii). Park elevation ranges from approximately 170 to 822 m a.s.1.

Fig. 1. Points surveyed for birds within Hollister Hills State Vehicle Recreation Area in central coastal California, USA. Inset map denotes the location of the study area in the western United States. Trail density was calculated within a $100-\mathrm{m}$ radius of each $30 \times 30 \mathrm{~m}$ cell center. State abbreviations are as follows: CA - California, NV - Nevada, OR - Oregon.

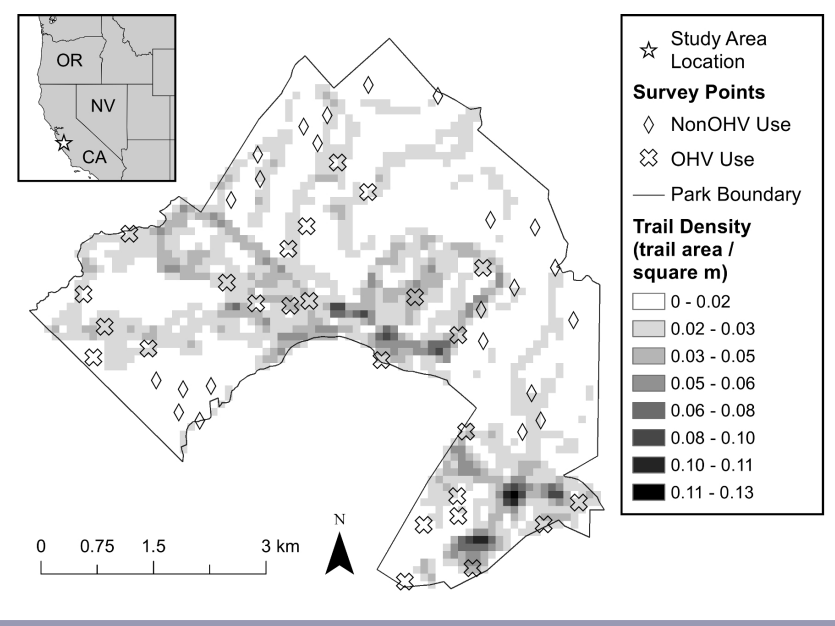

Off-highway vehicle use in the study area began in ca. 1947 to access parts of the property for hunting. The property was opened to motorcycle groups in the 1950s, and then in 1970, more broadly to the general public for OHV recreation. The State of California purchased most of the current Hollister Hills SVRA property in 1975 and acquired the remaining parcels in 1989 and 1993 (California State Parks Off-highway Motor Vehicle Division Report 1998, unpublished manuscript). The number of vehicles per month, including motorcycles, ATVs, and commercial passenger vehicles that entered the park peaked in November and early spring during the years of the study (http://ohv.parks.ca. gov/?page_id=26902). Despite the peak in November being higher, the total number of vehicles entering the park during the spring bird sampling period (April and May) was usually similar
(2012: 37,507; 2013:28,400; 2014: 28,831) to the vehicles entering in the winter (Jan. and Feb.) period (2012: 37,383; 2013: 5,545; 2014: 25,143).

\section{Bird surveys}

Birds were surveyed using identical methods based on 10-min point counts during spring 2012 and 2013 (mid April to early May) and the winters of 2012-2014 (mid December to mid February) at 48 points within the park. Surveys were conducted by volunteers with experience identifying local bird species by sight and sound. Most surveys ( $>90 \%)$ were conducted between 0700 and $1000 \mathrm{~h}$, and none extended beyond $1300 \mathrm{~h}$. These survey times correspond to approximately $1-4 \mathrm{~h}$ after sunrise and up to a maximum of $7 \mathrm{~h}$ during the spring, and $10 \mathrm{~min}$ to $3 \mathrm{~h}$ after sunrise and a maximum of $6 \mathrm{~h}$ during the winter. Distances to birds were estimated to the nearest meter and were collapsed to $50-\mathrm{m}$ bins and truncated at $250 \mathrm{~m}$ for analysis. When birds were present in an aggregation (cluster or flock), the observer estimated the distance to the center of the cluster. A stratified-random sampling design was used for placing points within three different habitats (grassland, oak woodland, or chaparral) across areas open and closed to OHV users (hereafter, OHV use and nonOHV use areas). A total of 25 points was sampled in OHV use areas and 23 points in nonOHV use areas.

We derived habitat types for each survey point using a hand digitized geographic information system (GIS) habitat layer for the park. The polygons for the habitat layer were initially generated using National Oceanic and Atmospheric Administration (NOAA) aerial photographs acquired in June 1993 and hand corrected by park staff to more accurately reflect ground observations. We classified habitat at each point according to the habitat that covered the largest proportion of a 100 -m radius circle centered on the sampling point. There were 10 chaparral, six grassland, and nine oak woodland sampling points in OHV use areas; and seven chaparral, 11 grassland, and five oak woodland sampling points in nonOHV use areas. Representative photos of these three habitat types are provided (Fig. 2).

\section{Trail cover}

For an index of OHV use intensity, we calculated the area covered by OHV trails in areas open to OHV users, which we refer to as "OHV trail cover." Our aim was to use OHV trail cover as a standin for intensity of OHV use because presumably areas that have more trails also have more OHV users. We note, however, that we had no data to test this relationship. We calculated OHV trail cover using a hand-digitized GIS layer that denoted trail locations and assigned the following trail widths based on estimates provided by park staff: track $=3 \mathrm{~m}$, four-wheel drive trail $=2.4$ $\mathrm{m}$, ATV trail $=1.2 \mathrm{~m}$, single track trail $=0.6 \mathrm{~m}$. We summed the area covered by all trails within the $100-\mathrm{m}$ radius around each point in areas of the park open to OHV use. Although some trails occur within areas of the park that were closed to OHV use (Fig. 1 ), they are used rarely by park staff as access roads or are open to nonmotorized visitor use. We chose not to include a measure of trail area from nonOHV use areas in our model given our objective was to determine effects of OHV use rather than trails per se. 
Fig. 2. Photographs of chaparral (a), grassland (b), and oak woodland (c) habitat types within Hollister Hills State Vehicular Recreation Area, California, USA.

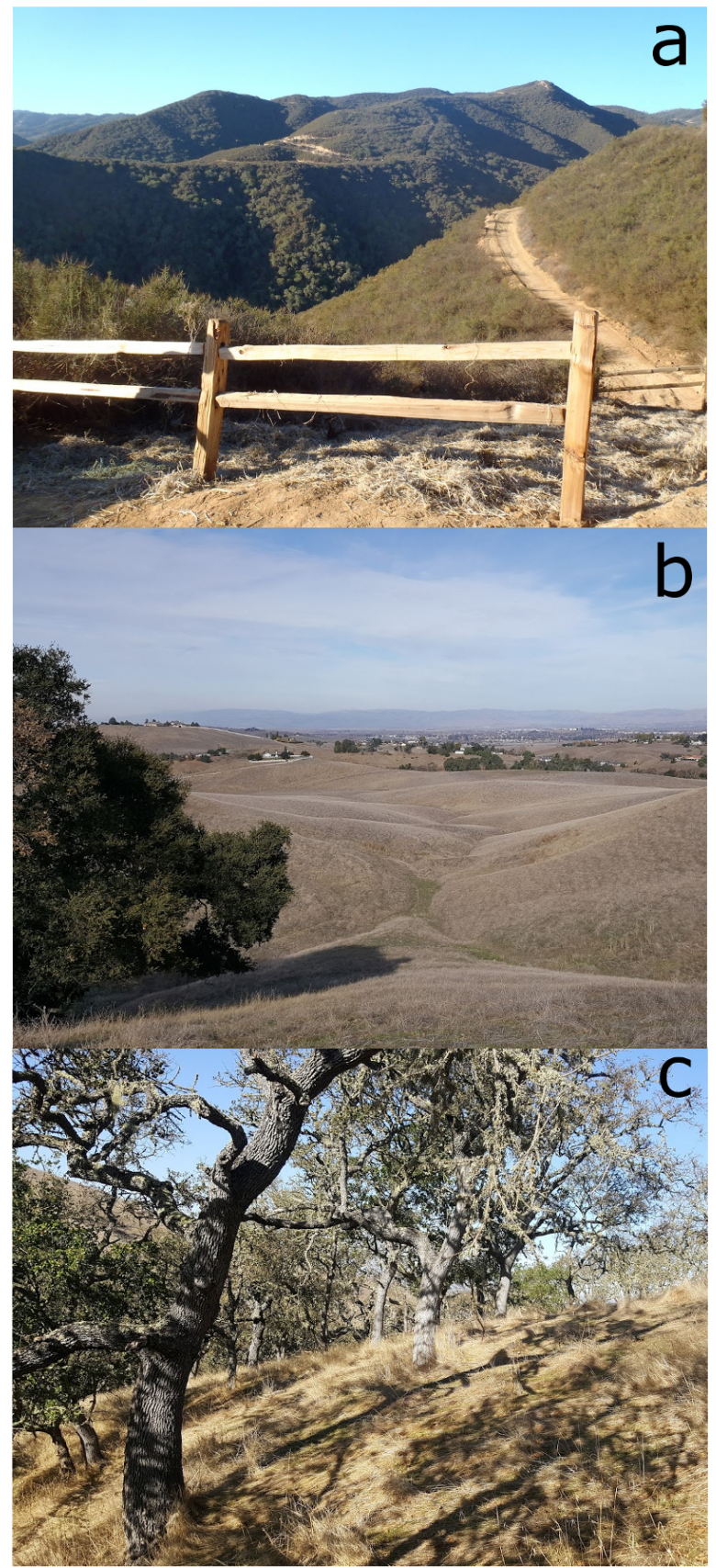

\section{Data analysis}

We implemented a hierarchical community distance sampling model (Sollmann et al. 2016) to evaluate the effect of OHV recreation on bird abundance while accounting for imperfect detection. Detection probability $p_{j t s}$ at point $j$, during year $t$, for species $s$ is estimated by modeling the number of detections of a bird species per distance band. The detection probability $p_{j t s}$ is used to estimate the true (and unobservable) abundance $N_{j t s}$ for each species by considering the observed abundance of birds $n_{j t s}$ to be distributed according to a binomial distribution such that:

$$
n_{j t s} \sim \operatorname{Binomial}\left(N_{j t s}, p_{j t s}\right)
$$

We modeled the number of clusters of individuals of each species (groups of flocking birds) observed at a point (including single individuals) rather than the total number of individuals because clustering violates the distance sampling assumption that individuals are detected independently of one another (Buckland et al. 1993). For conciseness throughout the remaining text, when we refer to bird "abundance," we are actually referring to the number of clusters of birds, not total number of birds at at a point. Most clusters were composed of only one bird $(68 \%)$ or two to three birds $(27 \%)$. Bird abundance was modeled as a function of the following covariates: OHV use (open or closed to OHV use), OHV trail cover ( $\mathrm{m}^{2}$ covered), habitat type (grassland, chaparral, and oak woodland), and year effect (categorical; 2012-2014). As the OHV use is directly related to $\mathrm{OHV}$ trail cover (i.e., points in nonOHV areas all had OHV trail cover of 0 ), we implemented two separate community models that included either the OHV use effect (see Appendix 1 for model code) or the OHV trail effect (see Appendix 2 for model code) to avoid collinearity (Farrar and Glauber 1967). We modeled count data collected during the spring and winter periods separately as community composition differs seasonally due to migration (Table 1). We considered an effect "significant" if the $95 \%$ credible intervals did not cross zero.

Bird species were only included in each seasonal community model if they were detected at least five times per year and season, and the observations were within $250 \mathrm{~m}$. These criteria were selected to maximize the number of species assessed while avoiding having the data dominated by a large number of species with very few detections. Simulation studies have found that species with fewer observations generally have more biased parameter estimates in community models than those with larger sample sizes (Sollmann et al. 2016). We truncated distance observations of birds to $250 \mathrm{~m}$ because this allowed us to include the maximum number of distance detections for the greatest number of species while also restricting the number of outlier distances that would make estimation of the detection function difficult. We grouped distances into $50 \mathrm{~m}$ bins because we observed evidence of rounding in the data, and binning has been shown to increase detection model robustness in such circumstances (Buckland et al. 1993).

We used Bayesian $P$ values (Gelman et al. 2004) to first select the distance detection function (half-normal or negativeexponential), then all combinations of covariates on detection (time of day, year of survey, habitat type, trail area, and an intercept only model). The detection model with the Bayesian $P$ value closest to 0.5 was included in the final community model for each season following the goodness-of-fit metric detailed by Sollmann et al. (2016). Our Bayesian $P$ value was calculated by comparing model residuals given the data and estimated parameters compared with residuals calculated using new data 
Table 1. Codes for bird species included in community models for Hollister Hills State Vehicular Recreation Area and used in Figs. 2, 3, and 4. An " $\mathrm{X}$ " in either the winter or spring column indicates that the species was included in that seasonal model.

\begin{tabular}{|c|c|c|c|c|}
\hline Code & Common name & Scientific name & Winter & Spring \\
\hline ACWO & Acorn Woodpecker & Melanerpes formicivorus & $\mathrm{X}$ & $\mathrm{X}$ \\
\hline AMCR & American Crow & Corvus brachyrhynchos & & $\mathrm{X}$ \\
\hline ANHU & Anna's Hummingbird & Calypte anna & & $\mathrm{X}$ \\
\hline ATFL & Ash-throated Flycatcher & Myiarchus cinerascens & & $\mathrm{X}$ \\
\hline BEWR & Bewick's Wren & Thryomanes bewickii & $\mathrm{X}$ & $\mathrm{X}$ \\
\hline BUOR & Bullock's Oriole & Icterus bullockii & & $\mathrm{X}$ \\
\hline BUSH & Bushtit & Psaltriparus minimus & & $\mathrm{X}$ \\
\hline CALT & California Towhee & Melozone crissalis & $\mathrm{X}$ & $\mathrm{X}$ \\
\hline CAQU & California Quail & Callipepla californica & & $\mathrm{X}$ \\
\hline CASJ & California Scrub-Jay & Aphelocoma californica & $\mathrm{X}$ & $\mathrm{X}$ \\
\hline CATH & California Thrasher & Toxostoma redivivum & $\mathrm{X}$ & $\mathrm{X}$ \\
\hline CORA & Common Raven & Corvus corax & $\mathrm{X}$ & $\mathrm{X}$ \\
\hline DEJU & Dark-eyed Junco & Junco hyemalis & $\mathrm{X}$ & $\mathrm{X}$ \\
\hline EUST & European Starling & Sturnus vulgaris & & $\mathrm{X}$ \\
\hline GCSP & Golden-crowned Sparrow & Zonotrichia atricapilla & $\mathrm{X}$ & \\
\hline HETH & Hermit Thrush & Catharus guttatus & $\mathrm{X}$ & \\
\hline HOFI & House Finch & Haemorhous mexicanus & & $\mathrm{X}$ \\
\hline HOWR & House Wren & Troglodytes aedon & & $\mathrm{X}$ \\
\hline HUVI & Hutton's Vireo & Vireo huttoni & & $\mathrm{X}$ \\
\hline LAZB & Lazuli Bunting & Passerina amoena & & $\mathrm{X}$ \\
\hline LEGO & Lesser Goldfinch & Spinus psaltria & & $\mathrm{X}$ \\
\hline MODO & Mourning Dove & Zenaida macroura & & $\mathrm{X}$ \\
\hline NOFL & Northern Flicker & Colaptes auratus & $\mathrm{X}$ & $\mathrm{X}$ \\
\hline OATI & Oak Titmouse & Baeolophus inornatus & $\mathrm{X}$ & $\mathrm{X}$ \\
\hline OCWA & Orange-crowned Warbler & Oreothlypis celata & & $\mathrm{X}$ \\
\hline RCKI & Ruby-crowned Kinglet & Regulus calendula & $\mathrm{X}$ & \\
\hline SOSP & Song Sparrow & Melospiza melodia & & $\mathrm{X}$ \\
\hline SPTO & Spotted Towhee & Pipilo maculatus & $\mathrm{X}$ & $\mathrm{X}$ \\
\hline STJA & Steller's Jay & Cyanocitta stelleri & $\mathrm{X}$ & $\mathrm{X}$ \\
\hline TUVU & Turkey Vulture & Cathartes aura & & $\mathrm{X}$ \\
\hline WBNU & White-breasted Nuthatch & Sitta carolinensis & $\mathrm{X}$ & \\
\hline WEBL & Western Bluebird & Sialia mexicana & $\mathrm{X}$ & $\mathrm{X}$ \\
\hline WIWA & Wilson's Warbler & Cardellina pusilla & & $\mathrm{X}$ \\
\hline WREN & Wrentit & Chamaea fasciata & $\mathrm{X}$ & $\mathrm{X}$ \\
\hline YRWA & Yellow-rumped Warbler & Setophaga coronata & $\mathrm{X}$ & \\
\hline
\end{tabular}

generated by the model. If the specified model is appropriate then residuals for the observed data will be higher than the residuals for the newly generated data approximately half of the time (i.e., $P$ value near 0.5 ).

Detection probability for each species and point count was calculated using only the portion of the fitted detection function spanning from 0 to $100 \mathrm{~m}$, rather than the full estimated detection function out to $250 \mathrm{~m}$. This was done because $250 \mathrm{~m}$ point count radii overlapped substantially between points (distance between sampling points was sometimes little more than $200 \mathrm{~m}$ ). In the interest of using independent data for modeling abundance, we only included counts of birds observed within $100 \mathrm{~m}$ in the abundance model and used distance observations of birds out to $250 \mathrm{~m}$ to model the detection function.

We implemented hierarchical community distance sampling models in a Bayesian framework through a Markov Chain Monte Carlo (MCMC) algorithm using the package jagsUI (Kellner 2016) to run JAGS (4.3.0; Plummer 2003) in the R programming environment (3.4.1; R Core Team 2017). We used vague priors for each parameter: uniform distribution $(\min =0, \max =10)$ for the negative binomial dispersion parameter; gamma distribution ( shape $=0.1$, rate $=0.1$ ) for precision of community hyperparameters; and normal distribution $($ mean $=0$, precision $=$ 0.01 ) for all other parameters. We ran three chains for 1,000 adaptation iterations with a burn-in of 20,000 , followed by a posterior draw of 5,000, and thinned every fifth iteration. We assumed models converged when the R-hat statistic for all monitored parameters was $<1.1$ (Gelman et al. 2004). We also checked for goodness-of-fit in both the abundance and detection portion of the model following the procedure outlined by Sollmann et al. (2016). See Appendix 3 for detailed model structure.

We used uncorrected counts of bird species from an unlimited radius around each point to calculate Shannon diversity (diversity; Shannon and Weaver 1949) for each point, season, and year by using the "diversity" function in the R package "vegan" (Oksanen et al. 2018). We used Shannon diversity because species richness, including occurrence of rare species, has a greater influence on the metric, in contrast to Simpson's diversity which is more influenced by dominant species (Morris et al. 2014). We were interested in understanding whether rare species continue to 
persist in OHV use areas. Waterbirds were excluded from these diversity calculations because we were solely interested in the effect on birds that primarily use land resources, as these species are likely most affected by vehicle use. We calculated the effect of OHV use on diversity values by using a linear mixed effects model with OHV use (use or nonuse) as a fixed effect and habitat type as a random intercept to account for the uneven number of points per habitat type. We calculated $95 \%$ confidence intervals around the OHV use effect by multiplying the effect by \pm 1.96 times SE.

\section{RESULTS}

Our community models included 18 and 30 bird species we considered to have sufficient data for abundance estimation in winter and spring, respectively (Table 1). The number of observations used for estimating individual bird species abundance parameters ranged widely within winter (min: 15, max: 117 ) and spring (min: 3, max: 68 ) and were similar to the range of observations used in a seabird hierarchical community distance sampling model (min: 1, max: 282) (Sollmann et al. 2016). Goodness-of-fit statistics indicated that our final abundance and detection models for each season adequately fit the data (Table 2). We detected a significant community-level (i.e., mean parameter estimate across all species) positive OHV use effect during the winter but not during the spring, and trail effect was significantly positive in both seasons (Fig. 3). The OHV use and trail effect were both smaller in the spring. Bird community abundance (i.e., mean of all species-level abundance) was significantly higher during the winters of 2013 and 2014 relative to 2012 , but there was no significant year effect in the spring (Fig. 3). Habitat had no significant effect on community abundance in the winter, but community abundance was significantly greater in oak woodland compared with chaparral habitat during the spring (Fig. 3).

Table 2. Bayesian $P$ values for evaluation of goodness-of-fit for detection and abundance components of models. Values closer to 0.5 indicate better fit and values $>0.1$ and $<0.9$ indicate adequate fit.

\begin{tabular}{lcc}
\hline \hline Model & Detection $P$ value & Abundance $P$ value \\
\hline Winter OHV use & 0.24 & 0.41 \\
Winter OHV trail cover & 0.22 & 0.39 \\
Spring OHV use & 0.48 & 0.71 \\
Spring OHV trail cover & 0.50 & 0.71 \\
\hline
\end{tabular}

Among individual species, the winter model indicated a significant positive effect of OHV use on Bewick's Wren, Wrentit, and California Thrasher, and significant positive effect of $\mathrm{OHV}$ trail cover for eight of 18 bird species assessed (Fig. 4). In spring, the effect of OHV use was only significantly positive for Wrentit (Fig. 5) out of 30 species assessed. We found a significant positive effect of OHV trail cover on seven species during the spring (Fig. 5). There was no significant difference in point-level diversity between $\mathrm{OHV}$ and nonOHV use areas during any season or year (Table 3, Fig. 6). However, mean diversity was consistently lower (although not statistically significant) in OHV use areas during spring in both years (Table 3 ). The difference in diversity was more variable during winter: OHV areas had lower diversity in 2013 and higher diversity in 2014 relative to nonOHV use areas,
Fig. 3. Estimates of community-level parameters (log scale) from winter and spring models. Pairs of symbols surrounding each dashed line indicate parameter estimates for models that included OHV use effect (circle) or OHV trail effect (triangle). Whiskers represent $95 \%$ credible intervals (CIs). Symbols are shaded black if CIs cross zero and gray if they do not. Parameters are as follows: intercept - intercept for the abundance model, OHV - OHV use effect, trail - OHV trail effect, 2013 - year effect for 2013 (relative to 2012), 2014 - year effect for 2014 (relative to 2012), Grassland - categorical effect of grassland (relative to chaparral), Oak - categorical effect of oak woodland (relative to chaparral).
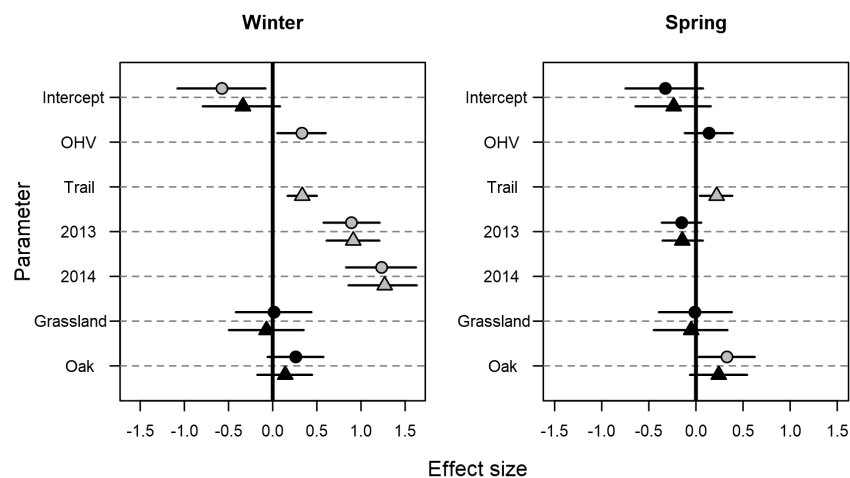

Fig. 4. Estimates of OHV use and OHV trail effects (log scale) on abundance of individual bird species in winter. See Table 1 for meaning of species' name codes. In both panels, species are ordered from strongest positive OHV use effect to strongest negative OHV use effect. Whiskers represent $95 \%$ credible intervals (CIs), and symbol fill represents whether an effect was significant (gray) or nonsignificant (black) depending on whether CIs overlap zero.

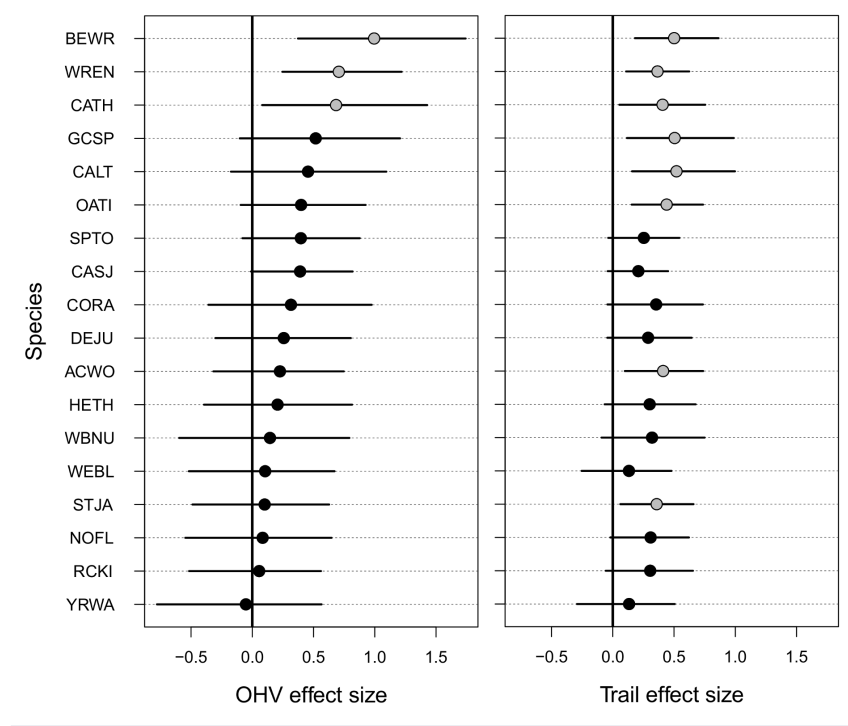


Fig. 5. Estimates of OHV use and OHV trail effects (log scale) on abundance of individual bird species in spring. See Table 1 for definitions of species' name codes. In both panels, species are ordered from strongest positive OHV use effect to strongest negative OHV use effect. Whiskers represent $95 \%$ credible intervals, and symbol fill represents whether an effect was significant (gray) or nonsignificant (black).
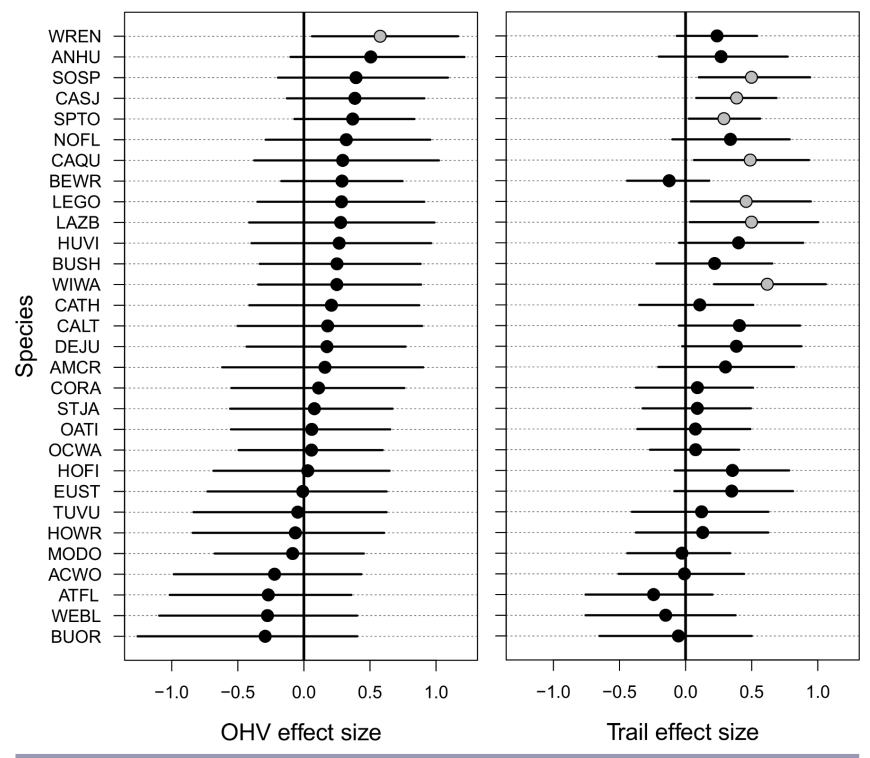

Table 3. Estimates of mean effect of OHV use on point level Shannon Diversity values in each season and year. Estimate of $\mathrm{OHV}$ use effects are from fitted linear mixed effects models that used diversity as a predictor (calculated from uncorrected bird abundances). Lower and upper CIs represent 95\% confidence intervals around the mean $( \pm 1.96 * \mathrm{SE})$.

\begin{tabular}{llccc}
\hline \hline Year & Season & $\begin{array}{c}\text { Mean OHV use } \\
\text { effect }\end{array}$ & Lower CI & Upper CI \\
\hline 2012 & Winter & -0.04 & -0.24 & 0.15 \\
2012 & Spring & -0.15 & -0.36 & 0.07 \\
2013 & Winter & -0.13 & -0.47 & 0.21 \\
2013 & Spring & -0.16 & -0.34 & 0.02 \\
2014 & Winter & 0.15 & -0.13 & 0.44 \\
\hline
\end{tabular}

although there were no statistically significant differences (Table 3). Bird species richness uncorrected for imperfect detection ranged from 37 to 50 total species at OHV points and 47 to 61 total species at nonOHV points during each season and year. Bird richness was higher at nonOHV use points (median of 8.5 more species) relative to OHV use points for four of five season-year combinations. However, two more species were observed at $\mathrm{OHV}$ use points than nonOHV use points in winter 2014.

Mean detection probability ranged widely for individual bird species in winter (range: $0.09-0.37$ ) and in spring (range: $0.07-$ 0.46; Appendices 4 and 5). A detection model with survey year and $\mathrm{OHV}$ trail cover produced the best fit to the detection function
Fig. 6. Comparison of Shannon Diversity values (calculated using uncorrected abundances) across survey points in nonOHV use and OHV use areas in winter and spring of 2012 (A, B), 2013 (C, D), and winter 2014 (E). Whiskers represent minimum and maximum diversity values (excluding outliers), lower and upper box bounds represent the first and third quartiles respectively, and the bold line in the center of the box represents the median. Dots beyond the whiskers represent outliers.

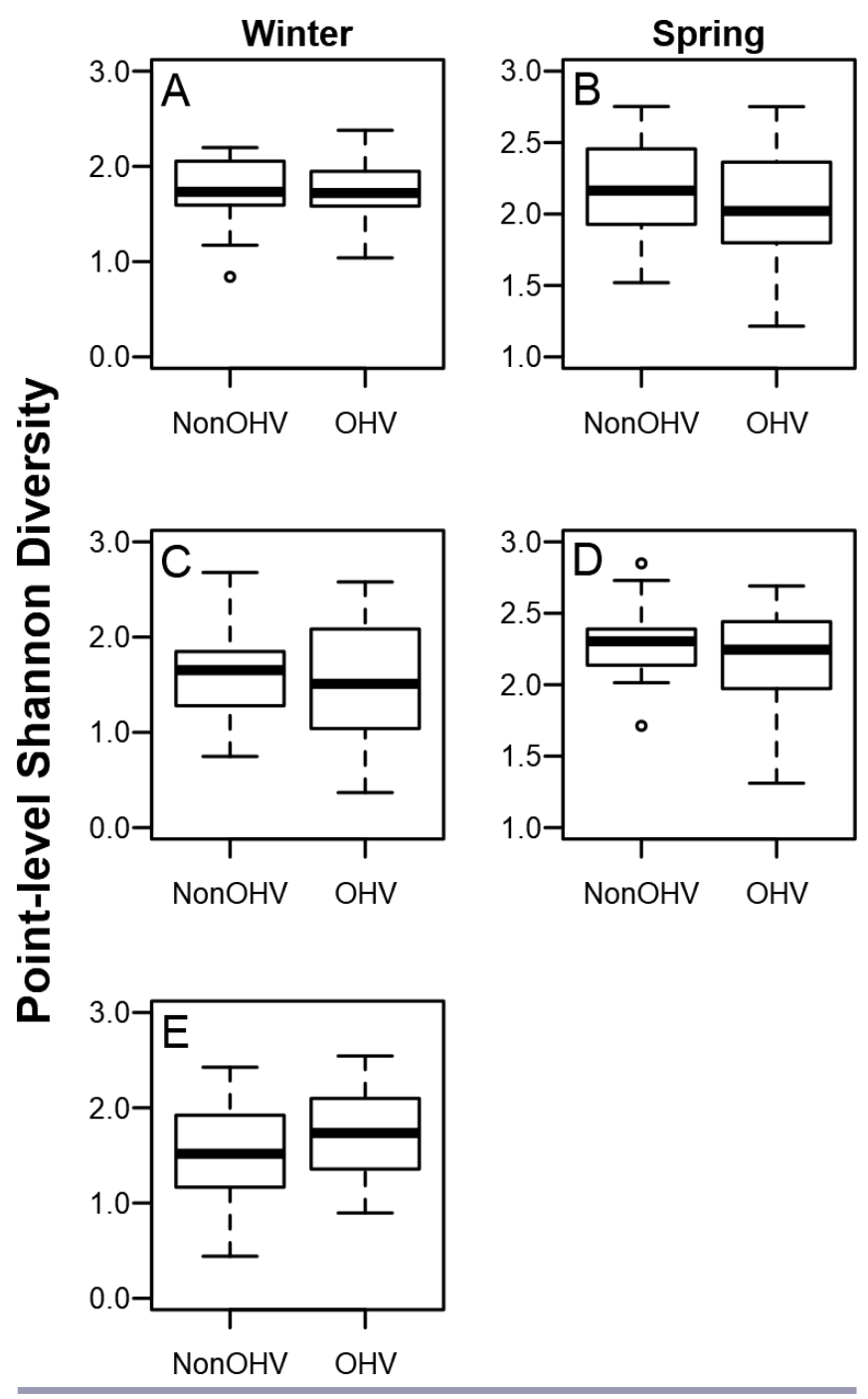

for winter, whereas a model with OHV trail cover alone was the best fit for spring (Appendices 6 and 7). In the winter, community model, detection probability declined on average with increasing amounts of OHV trail cover, and detection probability was lower in 2013 and 2014 relative to 2012 (Table 4). In the spring, community model detection probability also declined on average with OHV trail cover (Table 4). The negative-exponential was a better fit than the half-normal detection model for all species pooled, as indicated by Bayesian $P$ values (Appendix 8 ). 
Table 4. Estimates of mean effect of detection covariates on detection probability. LCI and UCI denote $95 \%$ Bayesian credible intervals around the mean. The parameter "trail" represents the effect of OHV trail cover on detection probability, and "2013" and "2014" denote the effect of year of survey on detection probability. Estimates are grouped by column into OHV and trail models, and by row for winter and spring models.

\begin{tabular}{|c|c|c|c|c|c|c|}
\hline \multirow[b]{2}{*}{ Parameter } & \multicolumn{3}{|c|}{ OHV model } & \multicolumn{3}{|c|}{ Trail model } \\
\hline & Mean & LCI & $\mathrm{UCI}$ & Mean & LCI & UCI \\
\hline \multicolumn{7}{|l|}{ Winter } \\
\hline intercept & -0.17 & -0.40 & 0.07 & -0.16 & -0.39 & 0.07 \\
\hline trail & -0.09 & -0.18 & 0.00 & -0.16 & -0.26 & -0.07 \\
\hline 2013 & -0.45 & -0.63 & -0.28 & -0.47 & -0.64 & -0.30 \\
\hline 2014 & -0.60 & -0.80 & -0.41 & -0.62 & -0.81 & -0.41 \\
\hline \multicolumn{7}{|l|}{ Spring } \\
\hline intercept & -0.32 & -0.48 & -0.16 & -0.32 & -0.48 & -0.16 \\
\hline trail & -0.05 & -0.13 & 0.02 & -0.12 & -0.20 & -0.04 \\
\hline
\end{tabular}

\section{DISCUSSION}

We found no evidence to support the predictions that OHV use or OHV trail cover negatively affected community-level bird abundance. On the contrary, some species appeared to be more abundant in areas open to OHV use and areas with greater OHV trail cover. However, fewer species had a positive response to $\mathrm{OHV}$ trail cover and OHV use in the winter compared with the spring. This suggests that birds may be more sensitive to OHV disturbance during the breeding season than during the winter. We note that this apparent seasonal effect was confounded by increased OHV use in the spring vs. the winter. Birds were consistently less diverse in OHV use areas relative to nonOHV use areas during the spring, which supports the idea that some species are less tolerant of disturbance during the breeding season. The generally lower species richness in OHV use areas suggests that although some bird species included in the community model responded positively to OHV use and OHV trail cover, other less-abundant species may have been negatively affected by nearby $\mathrm{OHV}$ recreation.

Our findings that no individual species exhibited significant negative responses to OHV use or OHV trail cover and some responded positively, ran largely counter to the findings of previous work in another California OHV use area. Barton and Holmes (2007) reported that no bird species were significantly more abundant closer to active OHV trails, and that two of 18 $(11.1 \%)$ bird species were significantly less abundant closer $(<100$ m) to vs. farther from active OHV trails. However, it is not unprecedented for a bird species to benefit from being close to disturbance. The White-rumped Shama (Copsychis malabaricus) had both higher nest success and postfledging survival at nest sites nearer to road edge in Asia (Angkaew et al. 2019). Although we did not study nesting, the White-rumped Shama study suggests that birds in our study area could also receive some fitness benefit from nesting closer to disturbance. Alternatively, OHV trail cover may not correlate well with amount of disturbance (i.e., OHV noise).

Three species in our study exhibited a positive relationship between abundance and OHV use during the winter (Bewick's
Wren, Wrentit, and California Thrasher), and one during the spring (Wrentit). This contrasts with other studies that have found only negative or neutral effects of OHV use on abundance of birds (Barton and Holmes 2007) or other vertebrates (Luckenbach and Bury 1983). It is unclear whether these abundance differences are due to habitat differences between OHV and nonOHV use areas. Our sample size was too small to model an interaction between habitat and OHV use in the model. The three positively affected bird species may be more abundant in OHV use areas due to a reduction in predation risk caused by noise interfering in audio communication of predators or predators avoiding noisy areas. In a study of noise effects on nesting, predation was lower for artificial nests placed near greater noise, and nest predators were less abundant in noisy areas compared with quieter areas (Francis et al. 2012). Barton and Holmes (2007) reported that proximity to $\mathrm{OHV}$ trail lowered predation risk (although not significantly) for some shrub-nesting birds. Indeed, all species that responded positively to OHV use in our study generally nest and forage in shrubs. Additionally, birds may be drawn to habitat edge (i.e., road edge) because of greater amounts of food (e.g., insects or seeds). Both insect abundance and seed production are often positively correlated with roads. Roads have been shown to provide foraging habitat and a warm surface for many bird species (Morelli et al. 2014). Herbivorous insects are more abundant on plants exposed to greater amounts of sunlight (Barber and Marquis 2011), and trees tend to produce more seeds at habitat edges vs. interiors of forest (Brotons and Herrando 2003). It has been experimentally demonstrated that insectivorous birds attempt to capture more insects at forest edge compared with the interior (Barbaro et al. 2014). However, it is unclear why Bewick's Wren and California Thrasher were significantly more abundant in OHV use areas during winter but not during spring. Perhaps, OHV use areas provide adult birds access to more food resources during the winter, but do not confer a reproductive benefit (i.e., higher reproductive success) to these species during the spring. Thus, birds may shift their territories seasonally between $\mathrm{OHV}$ use and nonOHV use areas.

The change in community OHV use effect from significantly positive in winter to nonsignificantly positive in spring provides limited support for the prediction that bird species may be more sensitive to disturbance during the breeding season. Apparent seasonal change in the OHV use effect may also have been driven by differences in park attendance, which was generally similar between winter (January and February) and spring (April and May), but was much lower during the winter of 2013. Therefore, we are unable to discern whether the seasonal difference in bird response to OHV use is because of difference in park attendance or because of birds are more sensitive to OHV disturbance during the breeding season.

The mechanism behind a negative OHV use effect on abundance in other studies is somewhat unclear. Noise is often considered a driver of declines in bird abundance or productivity, but the evidence for this effect is mixed. For some bird species, chronic noise has been found to reduce nesting densities in noisier areas, presumably because of interference in auditory signaling (Francis et al. 2009). Others have found through experimental manipulation that road noise alone reduces bird abundance even in the absence of any road surface, negatively affects body condition of individuals that persist in noisy areas, and increases foraging-vigilance behaviors, which reduces the ability of birds 
to maintain body condition (Ware et al. 2015). In addition, some boreal bird species have lower abundance closer to oil pads with active compressor stations (i.e., emitting loud noise) compared with oil pads with similar levels of forest edge but with no noise (Bayne et al. 2008). Contrary to the reduction of nest predation seen for some species in noisy areas (Francis et al. 2009), others have observed a negative relationship between noise and bird productivity (e.g., Halfwerk et al. 2011, Kight et al. 2012), although others have found no effects of noise on nest success (Bernath-Plaisted and Koper 2016). Unlike other well-controlled noise studies (e.g., Bayne et al. 2008, Ware et al. 2015), we did not have information on noise levels in addition to OHV trail cover, therefore we could not definitively say whether birds were responding positively or negatively to increased edge (i.e., OHV trail cover), noise levels, or both.

The presence of a positive OHV trail effect on community abundance during both seasons and positive OHV trail effects for a portion of species during the winter $(44.4 \%)$ and spring $(23.3 \%)$ run counter to other work evaluating avian responses to disturbance in OHV areas (Barton and Holmes 2007). However, it is not completely counter to studies of birds' responses to roads generally, which have found some positive effects for birds, particularly small birds and vultures (Fahrig and Rytwinski 2009, Morelli et al. 2014). Positive effects in some species may be driven by the same factors cited for the effect of OHV use (i.e., increased food availability and reproductive benefit). Our OHV trail cover metric is a more fine-scaled measure of disturbance by OHV users, although it is likely a better measure of habitat edge because we have no knowledge of how heavily individual trails are used within park. Our measure of intensity of OHV use (OHV trail cover), although related to the number of OHV users passing a given sampling point, may not reflect actual localized OHV activity if some trails are used much more frequently than others. In our study, we used OHV trail cover as a proxy for intensity of $\mathrm{OHV}$ use and detected some correspondence between the bird response to OHV use. However, a fairly sizeable portion of species responded positively to increased OHV trail cover. Our estimates of OHV trail cover within $100 \mathrm{~m}$ of a sampling point ranged from 0 to $5.6 \%$ of the surveyed area, and may not have exceeded some unknown threshold required to begin seeing a negative effect on bird abundance.

The lower diversity in OHV use areas relative to nonOHV use areas during the spring seems counterintuitive given the number of species we saw with greater abundance in areas with greater OHV trail cover. However, species that have smaller population sizes in the OHV use areas were less likely to be included in the community model because they did not meet our sample size threshold. Thus, our model may have been unintentionally biased toward inclusion of species with neutral or even positive effects of OHV use. The diversity measure calculated with uncorrected counts gives us a more complete view of the difference in diversity between $\mathrm{OHV}$ and nonOHV use areas, instead of calculating diversity with species common enough to model their abundance. Incorporating imperfect detection is usually more desirable than using uncorrected counts, but in this instance, we knew that species common within the study area tended to be positively associated OHV trail cover. We instead calculated diversity using uncorrected counts because we could include all species (even those with too few detections to model detectability). By collecting small amounts of additional information during a survey (e.g., time of first detection during survey) one can estimate abundance more accurately and generate less biased diversity measures (Yamaura and Royle 2017). Given our results, it seems likely that diversity was often lower in OHV use areas because a small subset of bird species could tolerate disturbance relatively well, potentially resulting in lower richness. Whereas, in nonOHV use areas, there could have been higher richness because species that were intolerant of OHV disturbance could persist.

Several other caveats about our results are important to note. The number of detections for some species was quite low, likely yielding low power to detect OHV effects on individual species. The community effects reflect the response of our modeled assemblage of species to OHV use and OHV trail cover, but are driven most strongly by the responses of species with larger number of detections. How one defines an assemblage (i.e., which species are included in the model) can influence whether model effects are found to be significant (Pacifici et al. 2014). One drawback of the hierarchical community distance sampling is that it assumes each species parameter (e.g., detection probability) comes from a shared distribution of parameter values informed by the community, which draws species-level effects toward a community mean (Sollmann et al. 2016). However, detection radii may also be roughly predicted using species phylogeny or traits such as body mass (Sólymos et al. 2018), potentially alleviating the issue of detection probabilities being drawn toward an overall (community) mean. The species-level responses of OHV use and $\mathrm{OHV}$ trail cover could be affected by the species assemblage of the model. For instance if there is a positive correlation between total bird abundance in the sampling area and OHV use (i.e., birds are more abundant overall if they have a more positive response to OHV use) then those more abundant species will be more heavily weighted in the model because of the larger number of observations. Species with a small number of observations will have their OHV effects pulled toward the overall (community) mean (Sollmann et al. 2016), which is positive in our hypothetical scenario, and may result in no significant negative effects being observed. One potential way to increase the number of detections would be to survey points earlier in the morning (we surveyed many points $>1 \mathrm{~h}$ after sunrise), as birds are more detectable earlier in the day (e.g., Rollfinke and Yahner 1990), or visit survey points multiple times during a season and alternate early morning visits. Additionally, those species with lower detection probabilities may have more variable estimates of abundance and therefore be more likely to have abundance parameter estimates that cross zero (i.e., which we have deemed nonsignificant).

The observed positive community OHV use and trail density effects on abundance do not necessarily mean that OHV use has no negative consequences for any bird species nesting within the park. Areas open to OHV use could attract birds in numbers equal to or exceeding those of undisturbed areas, but nest success and fledgling survival could be lower in OHV areas, creating an ecological trap (Gates and Gysel 1978). Animals use environmental cues to determine which habitat provides the maximum fitness benefit, such as nesting near habitat edge. However, with the advent of novel environments created by humans, cues that once signaled fitness benefits may now be detrimental (Robertson et al. 2013). For example, density of and nestling provisioning by Olive-sided Flycatchers (Contopus cooperi) were higher in selectively harvested forest compared with forest thinned naturally by wildfire, but nest success was lower in 
selectively harvested habitat presumably due to high nest predator abundance (Robertson and Hutto 2007). Although it appears that areas with greater OHV trail cover are attractive to some bird species, it is possible that repeated exposure to traffic noise from OHV riders may confer some fitness cost on birds in our study area, such as lower nestling or fledgling survival.

\section{CONCLUSION}

We found that bird abundance was positively or neutrally affected by OHV use and OHV trail cover at Hollister Hills SVRA. This may be attributable in part to methodological constraints: namely, that only species that are able to persist in the face of disturbance had sufficient number of observations to be modeled. Regardless, our findings reveal that careful management of vehicle use in OHV parks (e.g., restricting most $\mathrm{OHV}$ use to designated trails) appears somewhat capable of limiting the negative effect of disturbance on some bird species. In our study area, a key feature of successful management may be the relatively restricted area covered by $\mathrm{OHV}$ trails. Ensuring that OHV recreationists stay on designated trails may reduce additional trail proliferation and further limit some negative effects of OHVs such as reduced bird diversity. Much of the habitat cover in Hollister Hills SVRA (particularly the chaparral) naturally restricts riding to trails created by management, because riding off-trail into dense shrub cover is quite difficult. Future research should evaluate the effects of OHV use on the survival and reproduction of individual bird species, test for source-sink dynamics, and track bird movements relative to landscape metrics of disturbance such as vehicle noise. Monitoring OHV users' pattern of usage intensity throughout Hollister Hills SVRA could facilitate modeling of the relationship between bird abundance and noise disturbance and help identify any disturbance thresholds that may lead to deleterious effects on birds.

Responses to this article can be read online at: http://www.ace-eco.org/issues/responses.php/1422

\section{Acknowledgments:}

We thank the California State Parks Off-Highway Motor Vehicle Recreation Division for funding this work. This analysis would not have been possible without the cooperation of the staff of Hollister Hills State Vehicular Recreation Area. This is contribution number 632 of The Institute for Bird Populations.

\section{LITERATURE CITED}

Angkaew, R., W. Sankamethawee, A. J. Pierce, T. Savini, and G. A. Gale. 2019. Nesting near road edges improves nest success and post-fledging survival of White-rumped Shamas (Copsychus malabaricus) in northeastern Thailand. The Condor 121:1-15.. https://doi.org/10.1093/condor/duy013

Barbaro, L., B. Giffard, Y. Charbonnier, I. van Halder, and E. G. Brockerhoff. 2014. Bird functional diversity enhances insectivory at forest edges: a transcontinental experiment. Diversity and Distributions 20:149-159. https://doi.org/10.1111/ddi.12132
Barber, N. A., and R. J. Marquis. 2011. Light environment and the impacts of foliage quality on herbivorous insect attack and bird predation. Oecologia 166:401-409. https://doi.org/10.1007/ s00442-010-1840-9

Barton, D. C., and A. L. Holmes. 2007. Off-highway vehicle trail impacts on breeding songbirds in northeastern California. Journal of Wildlife Management 71:1617-1620. https://doi.org/10.2193/2006-026

Bayne, E. M., L. Habib, and S. Boutin. 2008. Impacts of chronic anthropogenic noise from energy-sector activity on abundance of songbirds in the boreal forest. Conservation Biology 22:11861193.. https://doi.org/10.1111/j.1523-1739.2008.00973.x

Bernath-Plaisted, J., and N. Koper. 2016. Physical footprint of oil and gas infrastructure, not anthropogenic noise, reduces nesting success of some grassland songbirds. Biological Conservation 204:434 441. https://doi.org/10.1016/j.biocon.2016.11.002

Borneman, T. E., E. T. Rose, and T. R. Simons. 2016. Off-road vehicles affect nesting behaviour and reproductive success of American Oystercatchers Haematopus palliatus. Ibis 158:261278. https://doi.org/10.1111/ibi.12358

Brotons, L., and S. Herrando. 2003. Effect of increased food abundance near forest edges on flocking patterns of Coal Tit Parus ater winter groups in mountain coniferous forests. Bird Study 50:106-111. https://doi.org/10.1080/00063650309461301

Buckland, S. T., D. R. Anderson, K. P. Burnham, and J. L. Laake. 1993. Distance sampling: estimating abundance of biological populations. Chapman and Hall, London, UK.

Bury, R. B., R. A. Luckenbach, and S. D. Busack. 1977. Effects of off-road vehicles on vertebrates in the California Desert. Wildlife Research Report 8, U. S. Fish and Wildlife Service, Washington, D.C., USA.

Canterbury, G. E., T. E. Martin, D. R. Petit, L. J. Petit, and D. F. Bradford. 2000. Bird communities and habitat as ecological indicators of forest condition in regional monitoring. Conservation Biology 14:544-558. https://doi.org/10.1046/ j.1523-1739.2000.98235.x

Cordell, H. K. 2012. Outdoor recreation trends and futures: a technical document supporting the Forest Service 2010 RPA Assessment. General Technical Report SRS-150, U.S. Forest Service, Southern Research Station, Asheville, NC, USA.

Fahrig, L., and T. Rytwinski. 2009. Effects of roads on animal abundance: an empirical review and synthesis. Ecology And Society 14: 21. https://doi.org/10.5751/ES-02815-140121

Farr, M. T., D. S. Green, K. E. Holekamp, G. J. Roloff, and E. F. Zipkin. 2019. Multispecies hierarchical modeling reveals variable responses of African carnivores to management alternatives. Ecological Applications 29:1-11. https://doi.org/10.1002/eap.1845

Farrar, D. E., and R. R. Glauber. 1967. Multicollinearity in regression analysis: the problem revisited. The Review of Economics and Statistics 49:92-107. https://doi.org/10.2307/1937887

Felton, S. K., K. H. Pollock, and T. R. Simons. 2018. Response of beach-nesting American Oystercatchers to off-road vehicles: an experimental approach reveals physiological nuances and decreased nest attendance. The Condor 120:47-62. https://doi. org/10.1650/CONDOR-17-84.1 
Francis, C. D., C. P. Ortega, and A. Cruz. 2009. Noise pollution changes avian communities and species interactions. Current Biology 19:1415-1419. https://doi.org/10.1016/j.cub.2009.06.052

Francis, C. D., C. P. Ortega, R. I. Kennedy, and P. J. Nylander. 2012. Are nest predators absent from noisy areas or unable to locate nests? Ornithological Monographs 74:101-110. https://doi. org/https://doi.org/10.1525/om.2012.74.1.101

Gates, J. E., and L. W. Gysel. 1978. Avian nest dispersion and fledging success in field-forest ecotones. Ecology 59:871-883. https://doi.org/10.2307/1938540

Gelman, A., J. B. Carlin, H. S. Stern, and D. B. Rubin. 2004. Bayesian data analysis. Second edition. CRC/Chapman and Hall, Boca Raton, Florida, USA. https://doi.org/10.1201/9780429258411

Goyert, H. F., B. Gardner, R. Sollmann, R. R. Veit, A. T. Gilbert, E. E. Connelly, and K. A. Williams. 2016. Predicting the offshore distribution and abundance of marine birds with a hierarchical community distance sampling model. Ecological Applications 26:1797-1815. https://doi.org/10.1890/15-1955.1

Halfwerk, W., L. J. M. Holleman, C. M. Lessells, and H. Slabbekoorn. 2011. Negative impact of traffic noise on avian reproductive success. Journal of Applied Ecology 48:210-219. https://doi.org/10.1111/j.1365-2664.2010.01914.x

Iknayan, K. J., M. W. Tingley, B. J. Furnas, and S. R. Beissinger. 2014. Detecting diversity: emerging methods to estimate species diversity. Trends in Ecology and Evolution 29:97-106. https://doi. org/10.1016/j.tree.2013.10.012

Jones, A. S., J. J. Anderson, B. G. Dickson, S. Boe, and E. S. Rubin. 2017. Off-highway vehicle road networks and kit fox space use. The Journal of Wildlife Management 81:230-237. https://doi. org/10.1002/jwmg.21204

Kellner, K. 2016. jagsUI: a wrapper around "rjags" to streamline "JAGS" analyses. [online] URL: https://CRAN.R-project.org

Kight, C. R., M. S. Saha, and J. P. Swaddle. 2012. Anthropogenic noise is associated with reductions in the productivity of breeding Eastern Bluebirds (Sialia sialis). Ecological Applications 22:19891996. https://doi.org/10.1890/12-0133.1

Luckenbach, R. A., and R. B. Bury. 1983. Effects of off-road vehicles on the biota of the Algodones Dunes, Imperial County, California. Journal of Applied Ecology 20:265-283. https://doi. org/10.2307/2403392

Madden, F. 2004. Creating coexistence between humans and wildlife: global perspectives on local efforts to address humanwildlife conflict. Human Dimensions of Wildlife 9:247-257. https://doi.org/10.1080/10871200490505675

Monz, C. A., D. N. Cole, Y. F. Leung, and J. L. Marion. 2010. Sustaining visitor use in protected areas: future opportunities in recreation ecology research based on the USA experience. Environmental Management 45:551-562. https://doi.org/10.1007/ s00267-009-9406-5

Morelli, F., M. Beim, L. Jerzak, D. Jones, and P. Tryjanowski. 2014. Can roads, railways and related structures have positive effects on birds? - A review. Transportation Research Part D: Transport and Environment 30:21-31. https://doi.org/10.1016/j. $\operatorname{trd} .2014 .05 .006$
Morris, E. K., T. Caruso, F. Buscot, M. Fischer, C. Hancock, T. S. Maier, T. Meiners, C. Müller, E. Obermaier, D. Prati, S. A. Socher, I. Sonnemann, N. Wäschke, T. Wubet, S. Wurst, and M. C. Rillig. 2014. Choosing and using diversity indices: insights for ecological applications from the German Biodiversity Exploratories. Ecology and Evolution 4:3514-3524. https://doi. org/10.1002/ece 3.1155

Oksanen, J., F. G. Blanchet, M. Friendly, R. Kindt, P. Legendre, D. McGlinn, P. R. Minchin, R. B. O'Hara, G. L. Simpson, P. Solymos, M. H. H. Stevens, E. Szoecs, and H. Wagner. 2018. vegan: Community ecology package. R package version 2.4-6.

Ouren, D. S., C. Haas, C. P. Melcher, S. C. Stewart, P. D. Ponds, N. R. Sexton, L. Burris, T. Fancher, and Z. H. Bowen. 2007. Environmental effects of off-highway vehicles on Bureau of Land Management lands: a literature synthesis, annotated bibliographies, extensive bibliographies, and internet resources: Open-File Report 2007-1352, United States Geological Survey, Fort Collins Science Center, CO, USA. https://doi.org/10.3133/ ofr20071353

Pacifici, K., E. F. Zipkin, J. A. Collazo, J. I. Irizarry, and A. Dewan. 2014. Guidelines for a priori grouping of species in hierarchical community models. Ecology and Evolution 4:877888. https://doi.org/10.1002/ece3.976

Perillo, A., L. G. Mazzoni, L. F. Passos, V. D. L. R. Goulart, C. Duca, and R. J. Young. 2017. Anthropogenic noise reduces bird species richness and diversity in urban parks. Ibis 159:638-646. https://doi.org/10.1111/ibi.12481

Plummer, M. 2003. JAGS: a program for analysis of Bayesian graphical models using Gibbs sampling. Pages 20-22 in K. Hornik, F. Leisch, and A Zeileis, editors. Proceedings of the 3rd International Workshop on Distributed Statistical Computing (DSC 2003). [online] URL: https://www.r-project.org/conferences/ DSC-2003/Proceedings/

Poiani, K. A., B. D. Richter, M. G. Anderson, and H. E. Richter. 2000. Biodiversity conservation at multiple scales: functional sites, landscapes, and networks. BioScience 50:133-146. https:// doi.org/10.1641/0006-3568(2000)050[0133:BCAMSF]2.3.CO;2

R Core Team. 2017. R: a language and environment for statistical computing. R Foundation for Statisical Computing, Vienna, Austria.

Robertson, B. A., and R. L. Hutto. 2007. Is selectively harvested forest an ecological trap for olive-sided flycatchers? The Condor 109: 109. https://doi.org/https://doi.org/10.1650/0010-5422(2007) 109[109:ishfae]2.0.co;2

Robertson, B. A., J. S. Rehage, and A. Sih. 2013. Ecological novelty and the emergence of evolutionary traps. Trends in Ecology and Evolution 28:552-560. https://doi.org/10.1016/j. tree.2013.04.004

Rollfinke, B. F., and R. H. Yahner. 1990. Effects of time of day and season on winter bird counts. The Condor 92:215-219. https:// doi.org/10.2307/1368402

Royle, J. A., D. K. Dawson, and S. Bates. 2004. Modeling abundance effects in distance sampling. Ecology 85:1591-1597. https://doi.org/10.1890/03-3127 
Sauer, J. R., P. J. Blank, E. F. Zipkin, J. E. Fallon, and F. W. Fallon. 2013. Using multi-species occupancy models in structured decision making on managed lands. Journal of Wildlife Management 77:117-127. https://doi.org/10.1002/jwmg.442

Shannon, C. E., and W. Weaver. 1949. The mathematical theory of communication. The University of Illinois Press, Urbana, Illinois, USA.

Sollmann, R., B. Gardner, K. A. Williams, A. T. Gilbert, and R. R. Veit. 2016. A hierarchical distance sampling model to estimate abundance and covariate associations of species and communities. Methods in Ecology and Evolution 7:529-537. https://doi.org/10.1111/2041-210X.12518

Sólymos, P., S. M. Matsuoka, E. M. Bayne, S. R. Lele, P. Fontaine, S. G. Cumming, D. Stralberg, F. K. A. Schmiegelow, and S. J. Song. 2013. Calibrating indices of avian density from nonstandardized survey data: making the most of a messy situation. Methods in Ecology and Evolution 4:1047-1058. https://doi. org/10.1111/2041-210X.12106

Sólymos, P., S. M. Matsuoka, D. Stralberg, N. K. S. Barker, and B. E. M. 2018. Phylogeny and species traits predict bird detectability. Ecography 41:1595-1603. https://doi.org/10.1111/ ecog.03415

Spaul, R. J., and J. A. Heath. 2017. Flushing responses of golden eagles (Aquila chrysaetos) in response to recreation. The Wilson Journal of Ornithology 129:834-845. https://doi.org/10.1676/16-165.1

Steenhof, K., J. L. Brown, and M. N. Kochert. 2014. Temporal and spatial changes in golden eagle reproduction in relation to increased off highway vehicle activity. Wildlife Society Bulletin 38:682-688. https://doi.org/10.1002/wsb.451

Summers, P. D., G. M. Cunnington, and L. Fahrig. 2011. Are the negative effects of roads on breeding birds caused by traffic noise? Journal of Applied Ecology 48:1527-1534. https://doi.org/https:// doi.org/10.1111/j.1365-2664.2011.02041.x

Ware, H. E., C. J. W. McClure, J. D. Carlisle, and J. R. Barber. 2015. A phantom road experiment reveals traffic noise is an invisible source of habitat degradation. Proceedings of the National Academy of Sciences 112:12105-12109. https://doi. org/10.1073/pnas.1504710112

White, A. M., E. F. Zipkin, P. N. Manley, and M. D. Schlesinger. 2013. Conservation of avian diversity in the Sierra Nevada: moving beyond a single-species management focus. PLOS ONE 8: e63088. https://doi.org/10.1371/journal.pone.0063088

Wisdom, M. J., H. K. Preisler, L. M. Naylor, R. G. Anthony, B. K. Johnson, and M. M. Rowland. 2018. Elk responses to trailbased recreation on public forests. Forest Ecology and Management 411:223-233. https://doi.org/10.1016/j.foreco.2018.01.032
Yamaura, Y., and J. A. Royle. 2017. Community distance sampling models allowing for imperfect detection and temporary emigration. Ecosphere 8: e02028. https://doi.org/10.1002/ ecs 2.2028

Zipkin, E. F., A. Dewan, and J. A. Royle. 2009. Impacts of forest fragmentation on species richness: a hierarchical approach to community modelling. Journal of Applied Ecology 46:815-822. https://doi.org/10.1111/j.1365-2664.2009.01664.x

Zipkin, E. F., J. A. Royle, D. K. Dawson, and S. Bates. 2010. Multispecies occurrence models to evaluate the effects of conservation and management actions. Biological Conservation 143:479-484. https://doi.org/10.1016/j.biocon.2009.11.016 
Appendix 1. Model for a community hierarchical distance sampling model written in the JAGS (Just Another Gibbs Sampler) language. This model was used for estimating the effect of OHV use (whether a region of the park was open to OHV users) on bird abundance.

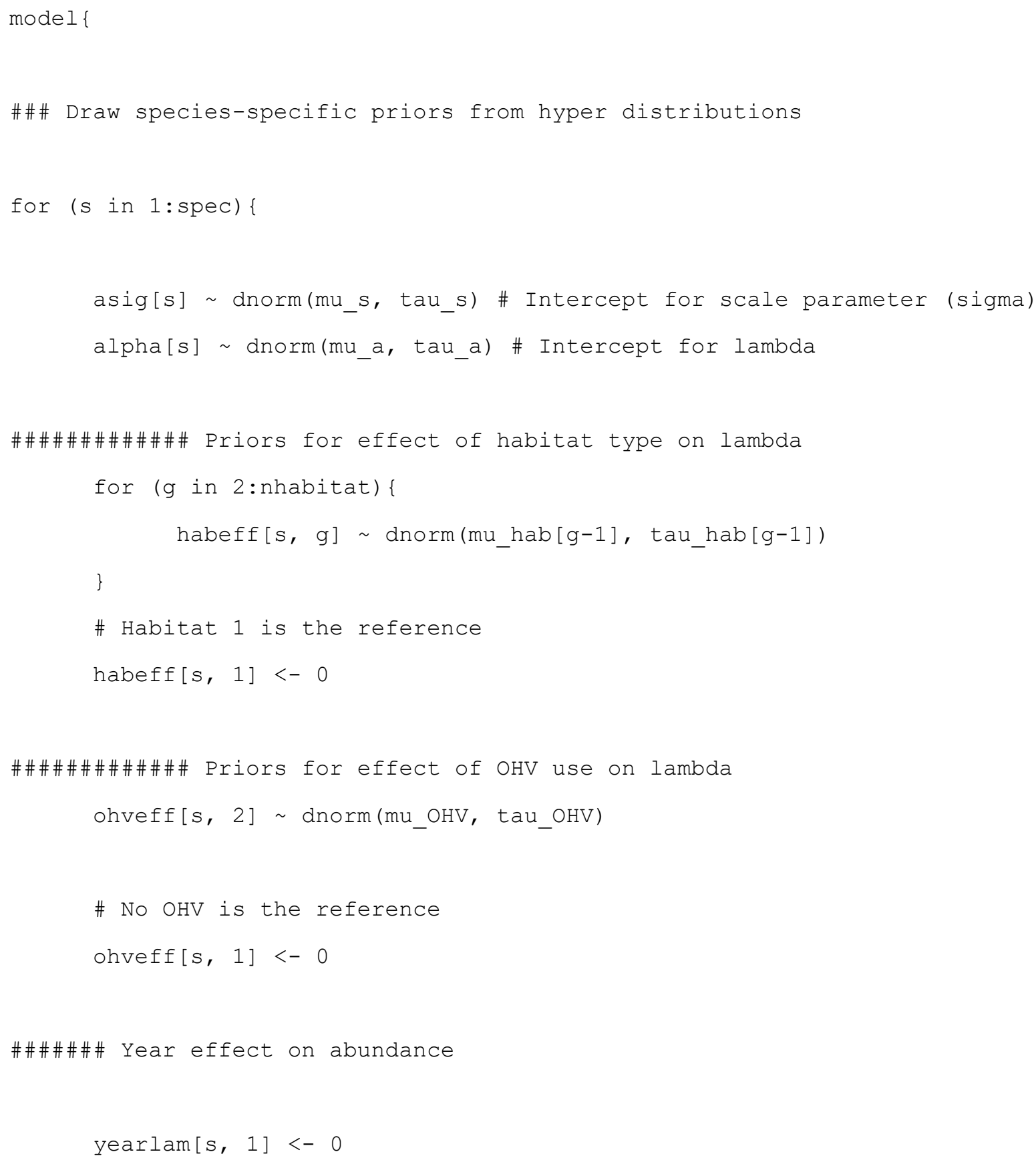




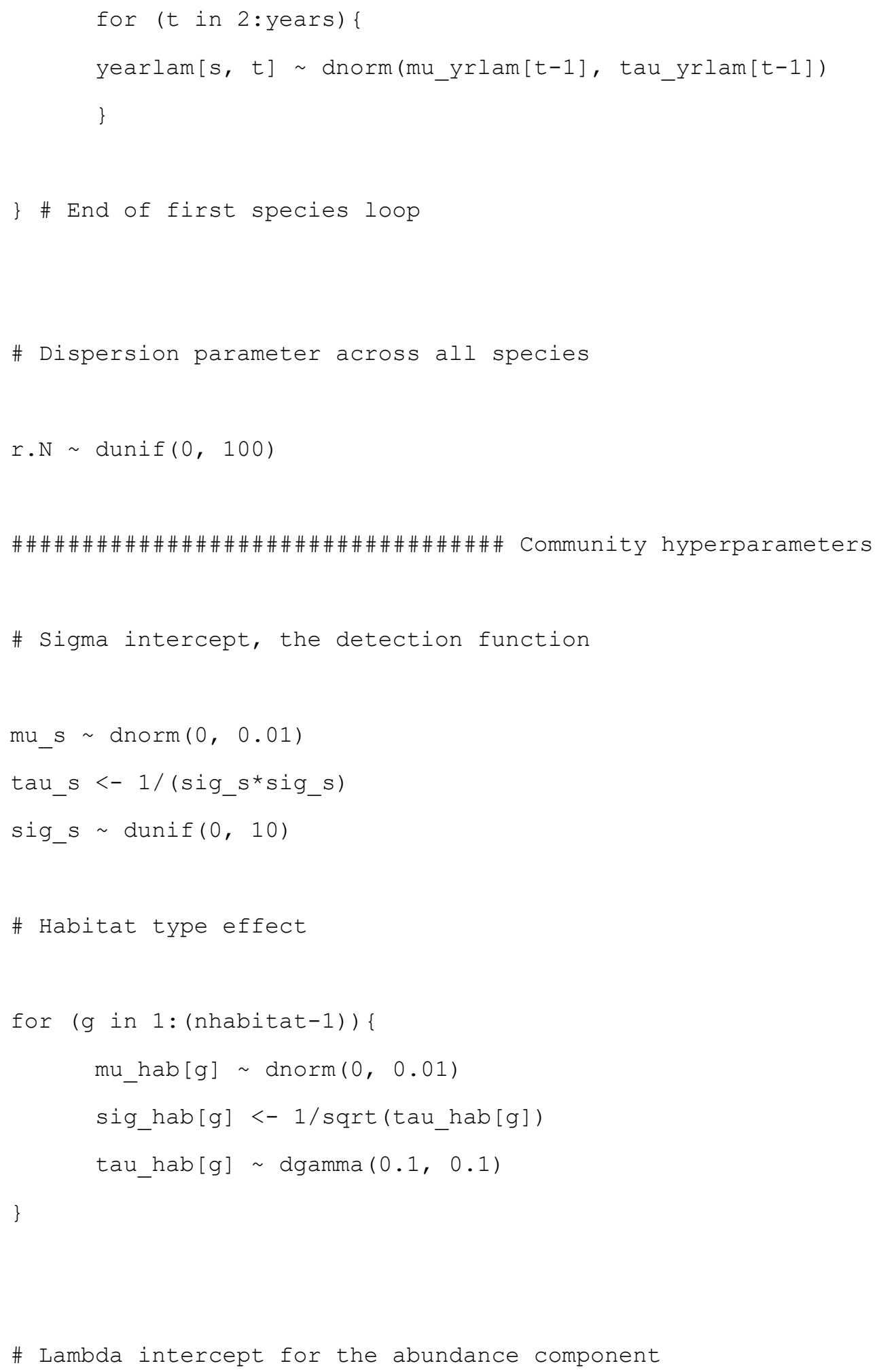




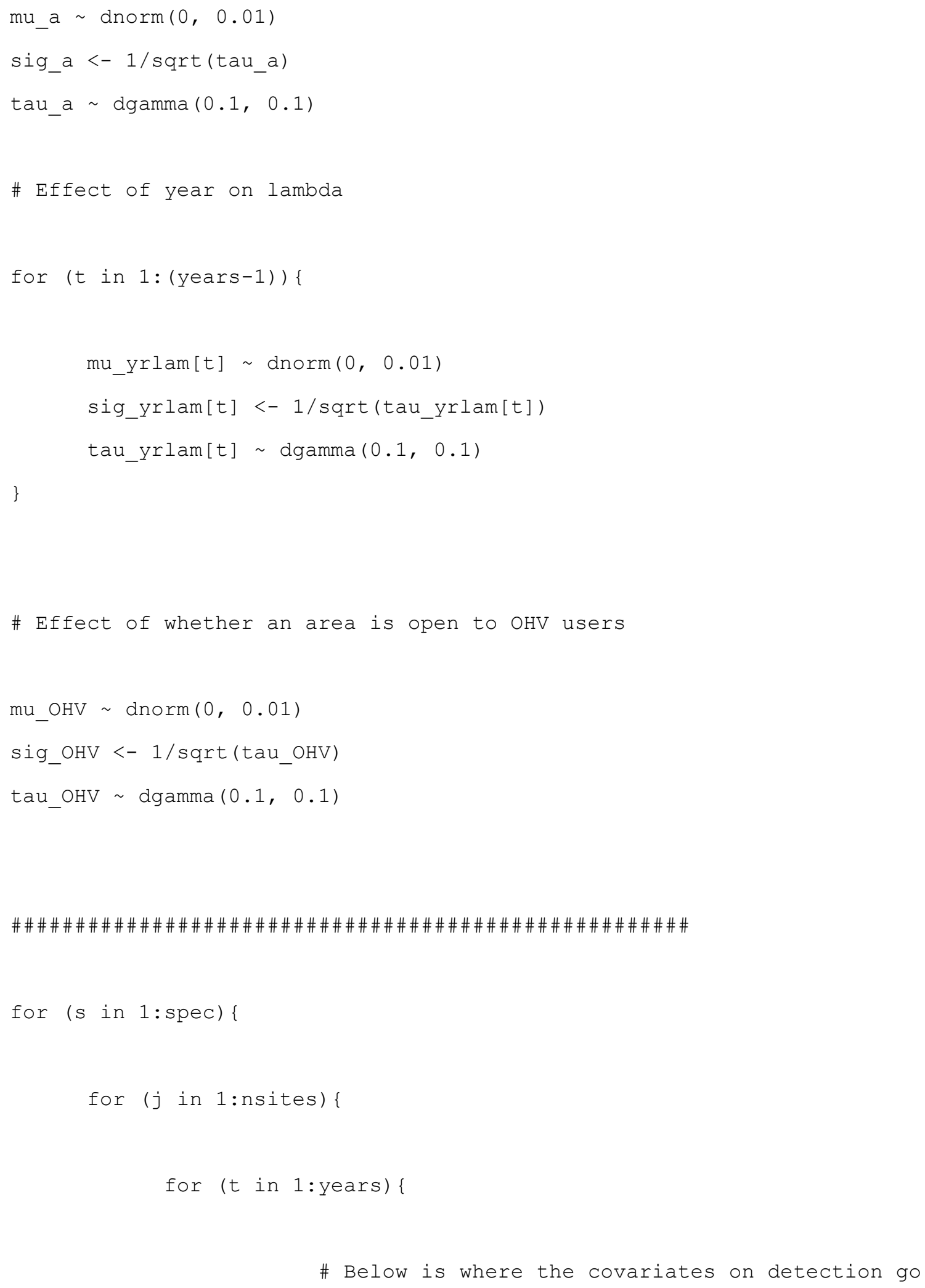




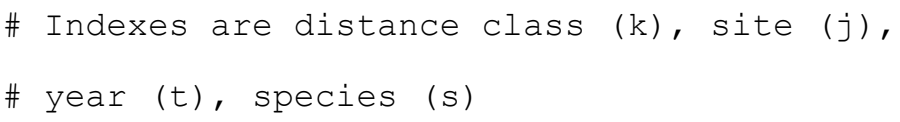




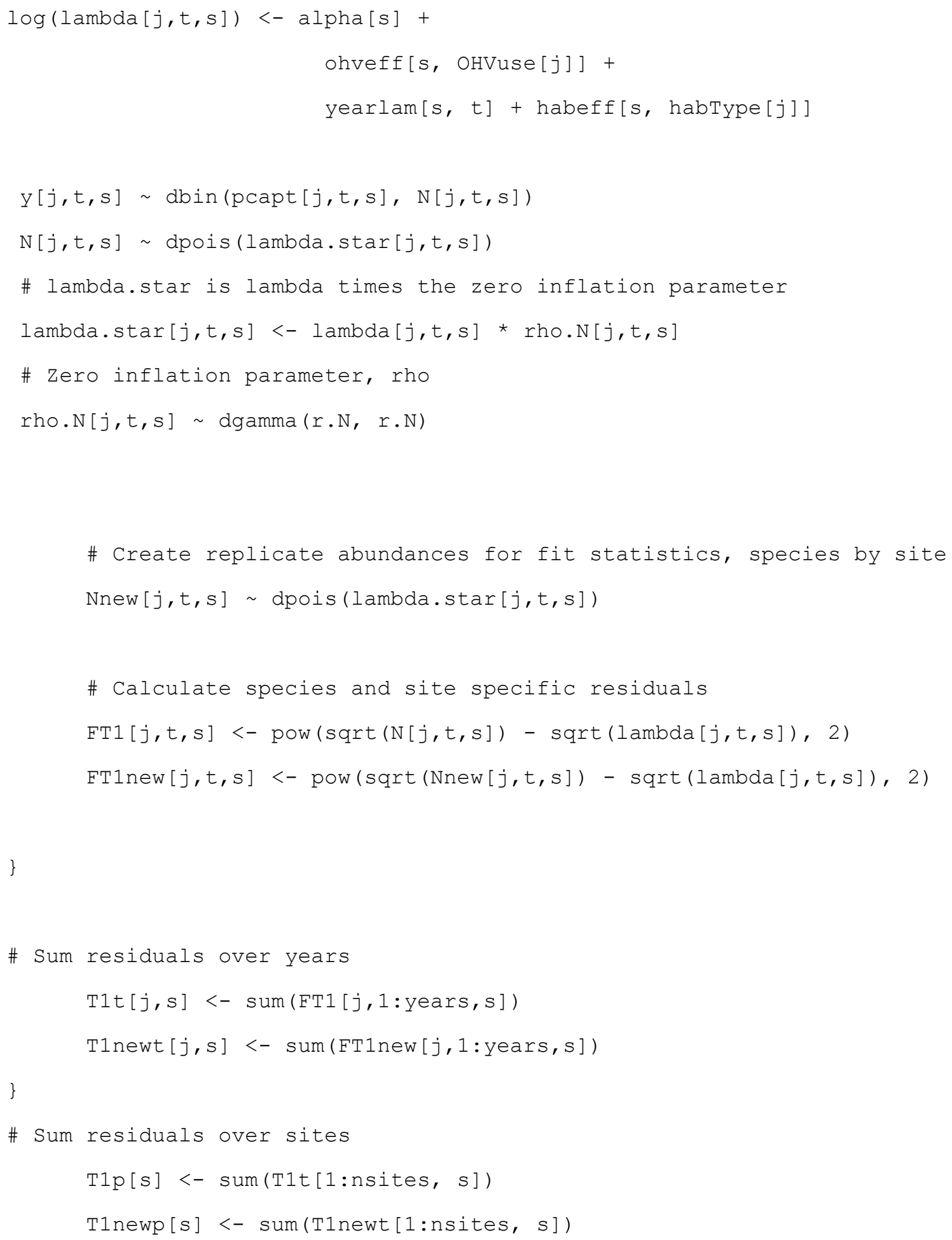


\# Sum residuals over species for final residuals

$\mathrm{T} 1<-\operatorname{sum}(\mathrm{T} 1 \mathrm{p}[1: \mathrm{spec}])$

T1 new<-sum (T1newp [1:spec])

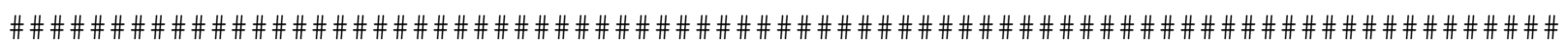
\#\# \# \# \# \# \#\# \# \# \# \# \#\# \# \# \#\# \#

\# Observation model

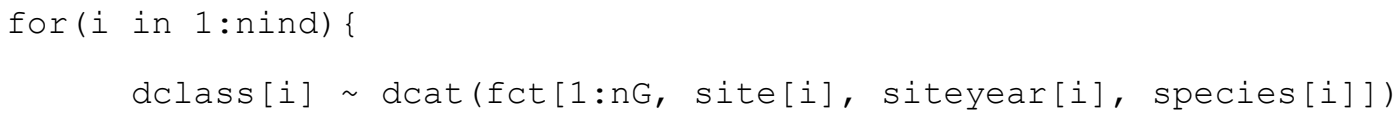



Appendix 2. Model for a community hierarchical distance sampling model written in the JAGS (Just Another Gibbs Sampler) language. This model was used for estimating the effect of OHV trail area on bird abundance.

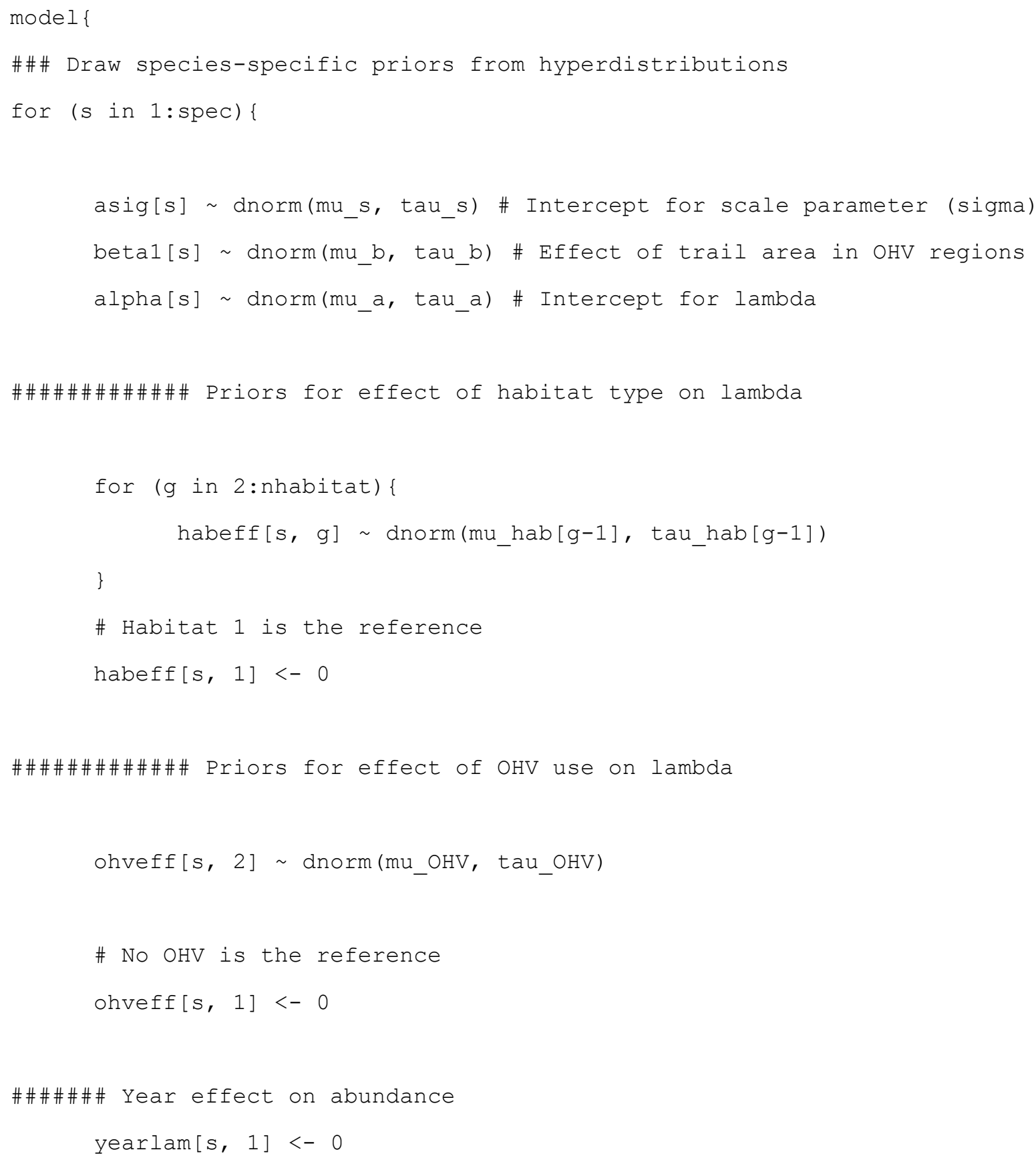




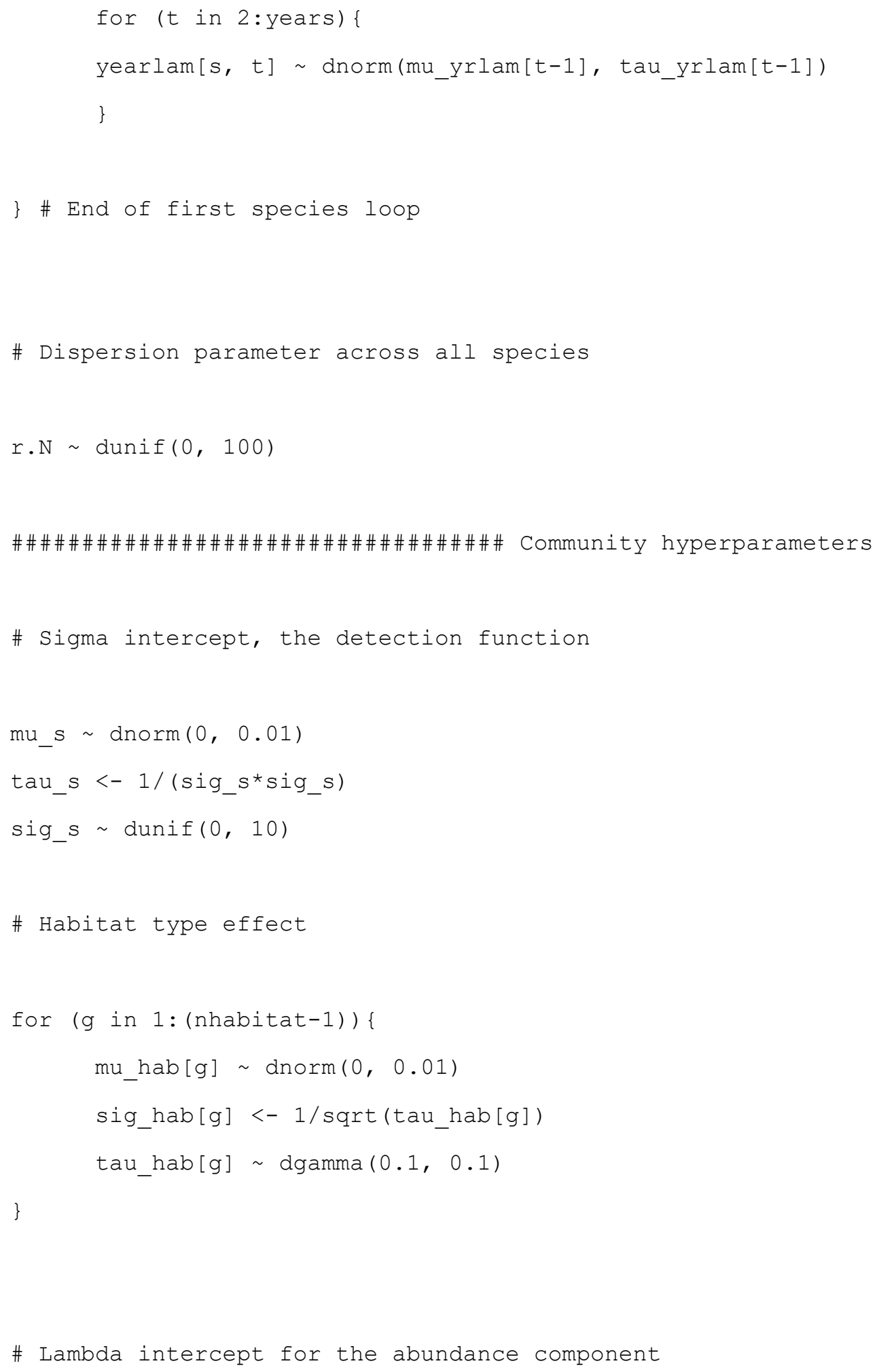




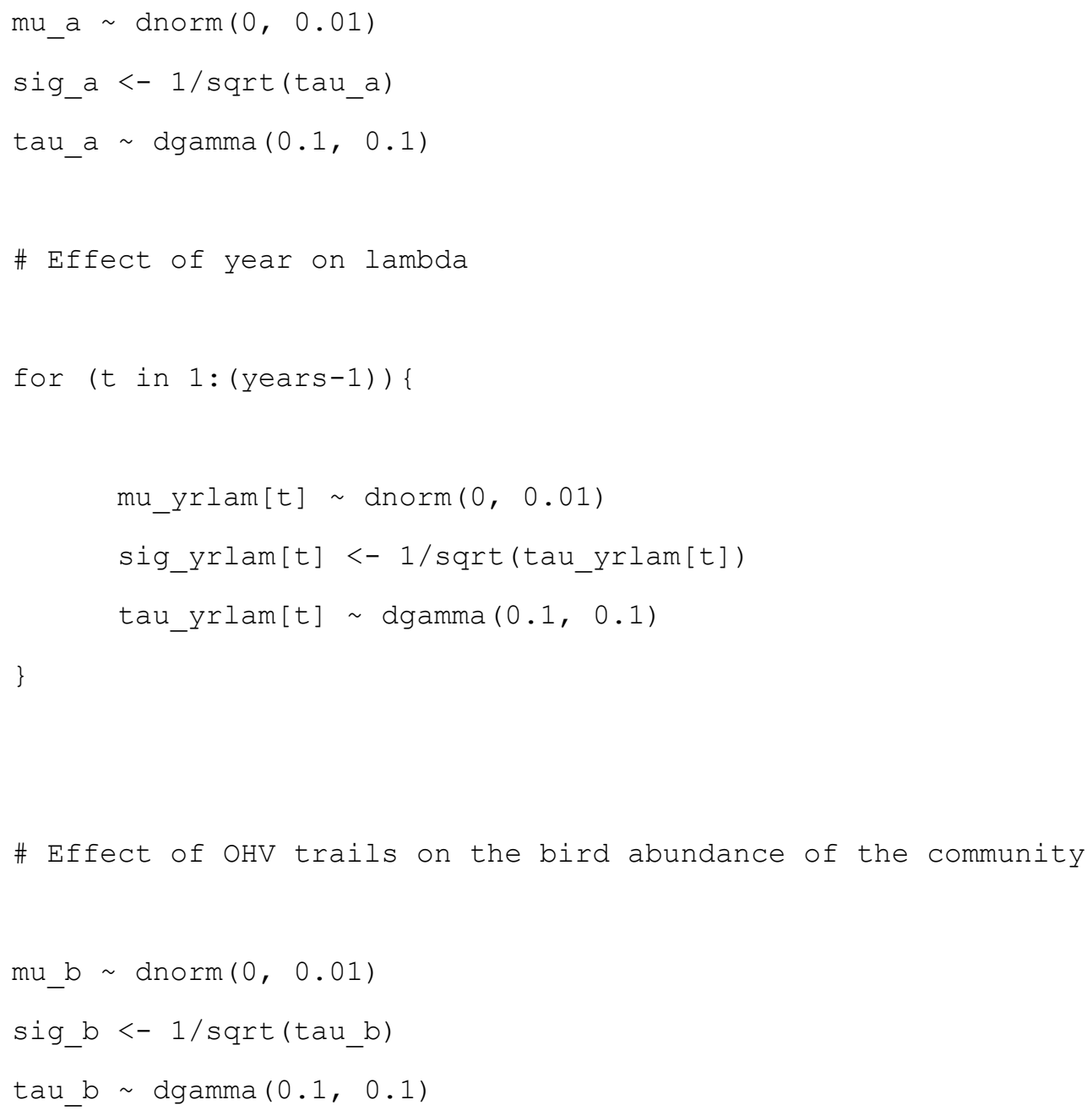




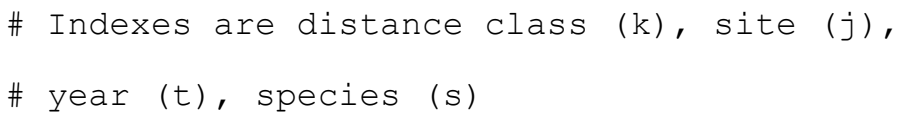




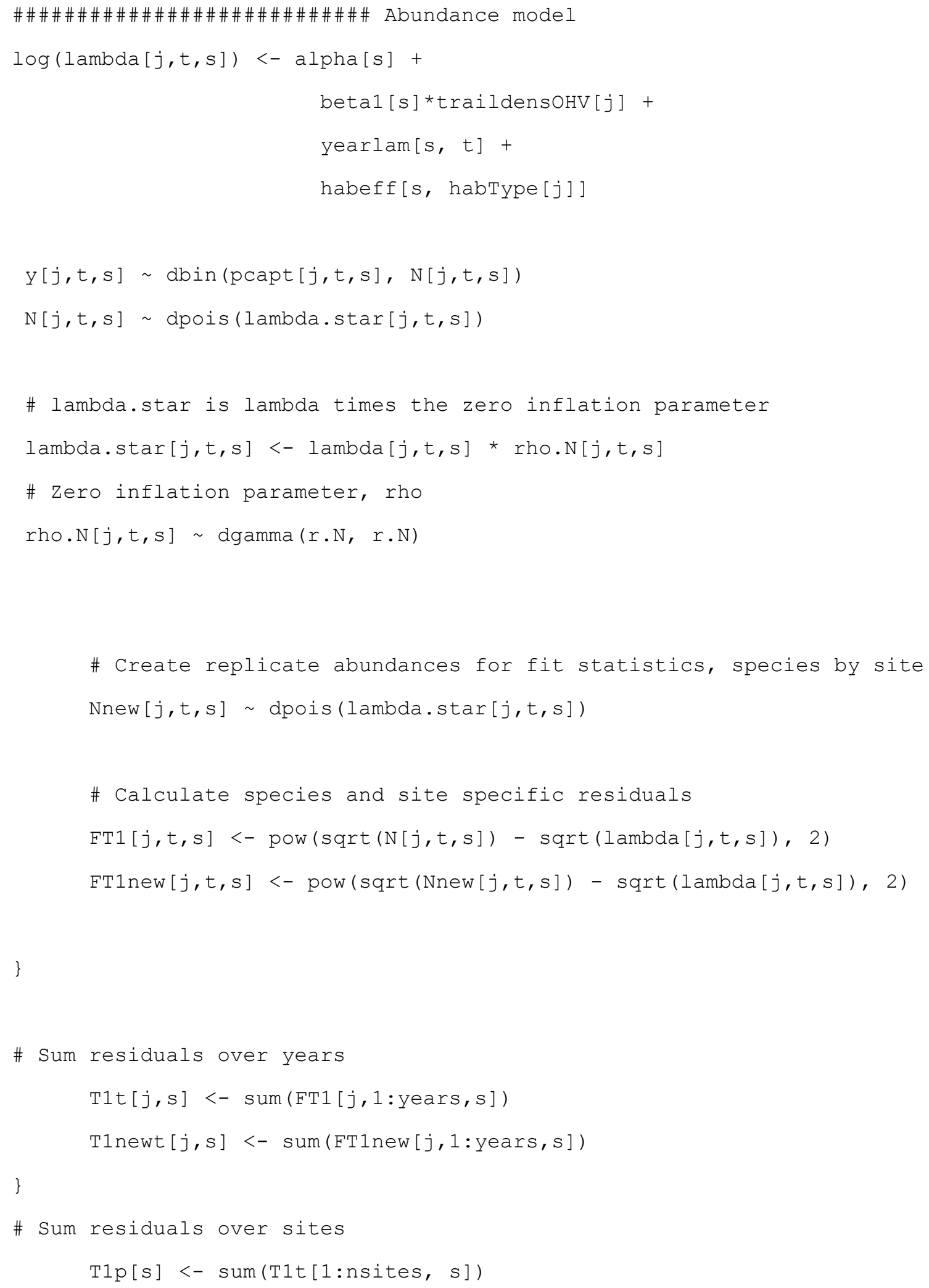


T1newp [s] <- sum(T1newt [1:nsites, s])

\}

\# Sum residuals over species for final residuals

$\mathrm{T} 1<-\operatorname{sum}(\mathrm{T} 1 \mathrm{p}[1: \mathrm{spec}])$

T1 new<-sum (T1newp [1:spec ])

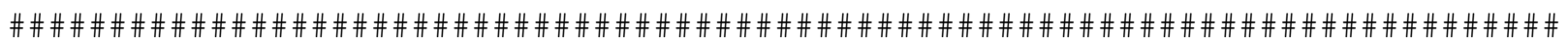
\#\# \# \# \# \# \#\# \#\# \# \# \#\# \#\# \#\#\# \#

\# Observation model

for (i in $1:$ nind) \{

$\operatorname{dclass}[i] \sim \operatorname{dcat}(f \mathrm{ct}[1: \mathrm{d}$, site[i], siteyear[i], species[i]])

\# Fit statistic for observation model

dclassnew[i] deat(fct[1:nG, site[i], siteyear[i], species[i]])

Tobsp $[i]<-$

pow(1- sqrt(fct[dclass[i], site[i], siteyear[i], species[i]]),2)

Tobspnew $[i]<-$

pow(1- sqrt(fct[dclassnew[i], site[i], siteyear[i], species[i]]),2)

\}

\# Summarize residuals across all sites, years, and species

Tobs <- sum(Tobsp $[1:$ nind $])$

Tobsnew <- sum(Tobspnew [1:nind])

\}

\# End of model description 
Appendix 3. Description of model structure.

Our models closely followed the model developed by Sollmann et al. (Sollmann et al. 2016). Bird abundance was modeled with a negative binomial distribution with a mean of $\lambda_{j, t, s}$ for point $j$, year $t$, and species $s$ and a dispersion parameter $r$. Bird abundances were modeled in separate models for spring and winter. There were also two separate models within each season, one which included a categorical OHV use effect, and one with a continuous covariate of trail area in OHV use areas. We modeled mean abundance $\lambda_{j, t, s}$ as a function of covariates such that:

$$
N_{j, t, s} \sim \operatorname{Negative~Binomial}\left(\lambda_{j, t, s}, r\right)
$$

For the categorical OHV use model:

$$
\log \left(\lambda_{j, t, s}\right)=\alpha_{0, s}+\text { OHVuse }_{s}+\text { Year }_{t, s}+\text { HABeff }_{k, s}
$$

For the trail area model:

$$
\log \left(\lambda_{j, t, s}\right)=\alpha_{0, s}+\alpha_{1, s} * \text { TrailArea }_{j}+\text { Year }_{t, s}+\text { HABeff }_{k, s}
$$

The $\mathrm{OHV}$ use $e_{s}$ term represents the categorical effect of OHV use on each species $s$ included in the model. Year $r_{t, s}$ represents the categorical effect of year $t$ of survey on species $s$, with the effect of $Y e a r_{1, S}$ set to zero for identifiability and corresponding to the first year surveyed. $H A B e f f_{k, s}$ represents the categorical effect of habitat class $k$ on on species $s$, with $H A B e f f_{1, s}$ set to zero for identifiability and corresponding to chaparral habitat. TrailArea $a_{j}$ represents the area covered by trails within a $100 \mathrm{~m}$ radius of a bird survey point $j$ at points open to OHV users. The $\alpha_{0, s}$ term is the species specific intercept and $\alpha_{1, s}$ is the coefficient representing the effect of OHV trail area on species $s$.

Detection probability $g(x)$ for each species was modeled as a function of distance $x$ to each bird observed, by either a negative-exponential function;

$$
g(x)=\exp \left(\frac{-x}{\sigma}\right)
$$

or half-normal function;

$$
g(x)=\exp \left(\frac{-x^{2}}{2 \sigma^{2}}\right)
$$

and covariates on detection were linked to the detection function such that:

$$
\log \left(\sigma_{j, t, s}\right)=\beta_{0, s}+\beta_{s}^{\prime} Y_{j, t}
$$


Where $\sigma_{j, t, s}$ is the scale parameter which describes how detection probability varies for species $s$ which was detected at point $j$ during year $t$. The parameter $\beta_{0, s}$ is a species specific intercept for $\sigma$, and $\beta_{s}^{\prime}$ represents all coefficients for each detection covariate $Y$ included in the model. The inclusion of either the negative-exponential or half-normal detection in the final model, and the determination of which detection covariates to include was based on the Bayesian $P$-value of the detection models. Detection probability was linked to abundance such that:

$$
n_{j t s} \sim \operatorname{Binomial}\left(N_{j t s}, p_{j t s}\right)
$$

where detection probability, $p_{j t s}$, is the output of the detection function $g(x)$ defined above and $n_{j t s}$ is the observed count of bird clusters (see Methods for definition) for for species $s$ which was detected at point $j$ during year $t$.

Parameters for each species, with the exception of the zero inflation parameter $r$, and their mean and standard deviation are drawn from a common distribution informed by all species in each model. This means we assumed that the estimate of a parameter came from an overall community distribution, which we call the hyperdistribution. For instance, the intercept for abundance $\alpha_{0, s}$ is drawn such that:

$$
\alpha_{0, s} \sim \operatorname{Normal}\left(\mu \alpha_{0}, \sigma \alpha_{0}\right)
$$

Hyperparameters for $\alpha_{0, s}$, mean $\mu \alpha_{0}$ and standard deviation $\sigma \alpha_{0}$ given precision $\tau \alpha_{0}$, are drawn such that:

$$
\begin{gathered}
\mu \alpha_{0} \sim \operatorname{Normal}(0,10) \\
\sigma \alpha_{0}=\frac{1}{\sqrt{\tau \alpha_{0}}} \\
\tau \alpha_{0} \sim \operatorname{gamma}(0.1,0.1)
\end{gathered}
$$

\section{References:}

Sollmann, R., B. Gardner, K. A. Williams, A. T. Gilbert, and R. R. Veit. 2016. A hierarchical distance sampling model to estimate abundance and covariate associations of species and communities. Methods in Ecology and Evolution 7:529-537. doi: 10.1111/2041-210X.12518 


\section{Appendix 4.}

Estimates of total detection probability ( $p$ estimate) within a $100 \mathrm{~m}$ radius circle, estimate of sigma for the negative-exponential detection function, and the total number of distances within a $250 \mathrm{~m}$ radius used to fit each detection model (n), for the winter models. We provide $95 \%$ Bayesian credible intervals (BCI). Note that because detection model estimates vary little between $\mathrm{OHV}$ only and trails only models, we only provided a single estimate of each parameter from the OHV trail model.

\begin{tabular}{llll}
\hline \hline Species & $p$ estimate $(95 \%$ BCI $)$ & Sigma estimate $(\mathrm{m})(95 \%$ BCI $)$ & $\mathrm{n}$ \\
\hline ACWO & $0.25(0.09,0.44)$ & $41.01(20.40,72.70)$ & 60 \\
BEWR & $0.15(0.05,0.31)$ & $27.82(15.38,48.81)$ & 47 \\
CALT & $0.13(0.03,0.28)$ & $24.43(11.25,43.94)$ & 34 \\
CATH & $0.19(0.07,0.37)$ & $32.97(17.84,57.97)$ & 26 \\
CORA & $0.37(0.15,0.60)$ & $62.28(27.57,117.20)$ & 26 \\
DEJU & $0.12(0.04,0.27)$ & $23.87(13.28,42.57)$ & 47 \\
GCSP & $0.08(0.02,0.20)$ & $18.51(9.04,33.79)$ & 23 \\
HETH & $0.09(0.02,0.22)$ & $20.00(9.48,36.65)$ & 34 \\
NOFL & $0.33(0.14,0.55)$ & $54.12(26.31,101.85)$ & 52 \\
OATI & $0.15(0.07,0.30)$ & $28.05(17.38,46.57)$ & 67 \\
RCKI & $0.08(0.02,0.19)$ & $18.80(9.69,32.70)$ & 54 \\
SPTO & $0.14(0.05,0.30)$ & $26.56(14.99,46.49)$ & 78 \\
STJA & $0.22(0.09,0.41)$ & $36.68(20.62,64.80)$ & 53 \\
WBNU & $0.23(0.06,0.43)$ & $38.87(15.91,70.47)$ & 23 \\
WEBL & $0.21(0.08,0.38)$ & $35.40(18.20,60.86)$ & 46 \\
CASJ & $0.24(0.11,0.41)$ & $39.98(23.14,64.98)$ & 158 \\
WREN & $0.32(0.13,0.56)$ & $54.07(25.50,104.50)$ & 127 \\
YRWA & $0.11(0.03,0.24)$ & $22.41(11.74,38.49)$ & 26 \\
\hline
\end{tabular}




\section{Appendix 5.}

Estimates of total detection probability ( $p$ estimate) within a 100 m radius circle, estimate of sigma for the negative-exponential detection function, and the total number of distances used to fit each detection model (n), for the spring models. We provide 95\% Bayesian credible intervals (BCI). Note that because detection model estimates vary little between OHV only and trails only models, we only provided a single estimate of each parameter from the OHV trail model.

\begin{tabular}{|c|c|c|c|}
\hline Species & $p$ estimate $(95 \% \mathrm{BCI})$ & Sigma estimate (m) (95\% BCI) & $\mathrm{n}$ \\
\hline ACWO & $0.32(0.17,0.44)$ & $50.22(29.59,72.50)$ & 30 \\
\hline AMCR & $0.40(0.25,0.58)$ & $66.78(40.25,112.12)$ & 12 \\
\hline ANHU & $0.07(0.03,0.14)$ & $17.79(11.07,25.85)$ & 25 \\
\hline ATFL & $0.28(0.18,0.40)$ & $45.35(31.29,64.10)$ & 29 \\
\hline BEWR & $0.20(0.15,0.26)$ & $34.11(27.17,42.07)$ & 77 \\
\hline BUOR & $0.13(0.04,0.24)$ & $25.28(12.66,39.36)$ & 12 \\
\hline BUSH & $0.10(0.05,0.18)$ & $21.46(14.72,30.66)$ & 22 \\
\hline CALT & $0.23(0.13,0.36)$ & $37.92(25.23,57.23)$ & 15 \\
\hline CAQU & $0.36(0.23,0.52)$ & $58.57(37.38,92.00)$ & 17 \\
\hline CATH & $0.26(0.16,0.38)$ & $41.25(28.75,60.77)$ & 22 \\
\hline CORA & $0.43(0.31,0.59)$ & $71.94(47.91,112.78)$ & 30 \\
\hline DEJU & $0.14(0.06,0.23)$ & $26.10(16.50,36.93)$ & 25 \\
\hline EUST & $0.16(0.07,0.26)$ & $28.36(18.00,41.58)$ & 16 \\
\hline HOFI & $0.22(0.13,0.34)$ & $37.10(25.26,52.71)$ & 22 \\
\hline HOWR & $0.24(0.09,0.37)$ & $38.82(20.27,58.20)$ & 18 \\
\hline HUVI & $0.22(0.11,0.35)$ & $35.93(22.76,54.91)$ & 13 \\
\hline LAZB & $0.23(0.11,0.36)$ & $37.58(22.82,57.09)$ & 16 \\
\hline LEGO & $0.11(0.06,0.19)$ & $23.11(15.86,31.97)$ & 25 \\
\hline MODO & $0.28(0.18,0.38)$ & $44.40(31.35,59.90)$ & 44 \\
\hline NOFL & $0.32(0.17,0.46)$ & $51.00(30.25,76.77)$ & 26 \\
\hline OATI & $0.15(0.08,0.24)$ & $28.15(18.29,38.74)$ & 27 \\
\hline OCWA & $0.20(0.14,0.28)$ & $33.68(25.95,44.11)$ & 46 \\
\hline SOSP & $0.11(0.05,0.20)$ & $22.73(15.10,33.09)$ & 23 \\
\hline SPTO & $0.23(0.17,0.30)$ & $37.71(29.90,46.75)$ & 82 \\
\hline STJA & $0.22(0.13,0.33)$ & $36.64(25.41,52.36)$ & 22 \\
\hline TUVU & $0.46(0.28,0.63)$ & $78.23(44.73,131.82)$ & 20 \\
\hline WEBL & $0.17(0.07,0.28)$ & $29.48(17.78,43.78)$ & 15 \\
\hline CASJ & $0.26(0.17,0.34)$ & $41.35(29.70,53.83)$ & 58 \\
\hline WIWA & $0.14(0.08,0.22)$ & $26.41(18.75,36.74)$ & 23 \\
\hline WREN & $0.38(0.29,0.47)$ & $59.98(45.86,79.30)$ & 74 \\
\hline
\end{tabular}




\section{Appendix 6.}

Bayesian p-values for all formulations of detection covariates for winter community models. Values closer to 0.5 indicate better fit. Detection covariates are as follows: none - only an intercept was included; time - hours after sunrise for the day of survey; year - categorical effect of year of survey, which was intended as a stand-in for observer effect; hab - categorical effect of habitat class, which was identical to the habitat covariate included in the final model; and trail - the area covered by all trails within $100 \mathrm{~m}$ of each survey point center in OHV use areas.

\begin{tabular}{lll}
\hline \hline Covariates & Bayesian P-value & Distance from 0.5 \\
\hline year + trail & 0.20 & 0.30 \\
time + year +hab & 0.19 & 0.31 \\
time + year + trail & 0.19 & 0.31 \\
year & 0.19 & 0.31 \\
year + hab + trail & 0.19 & 0.31 \\
time + year & 0.17 & 0.33 \\
year + hab & 0.17 & 0.33 \\
hab + trail & 0.11 & 0.39 \\
time + hab + trail & 0.11 & 0.39 \\
time + trail & 0.11 & 0.39 \\
trail & 0.09 & 0.41 \\
time & 0.08 & 0.42 \\
none & 0.07 & 0.43 \\
hab & 0.06 & 0.44 \\
time + hab & 0.06 & 0.44 \\
\hline
\end{tabular}




\section{Appendix 7.}

Bayesian p-values for all formulations of detection covariates for spring community models. Values closer to 0.5 indicate better fit. Detection covariates are as follows: none - only an intercept was included; time - hours after sunrise for the day of survey; year - categorical effect of year of survey, which was intended as a stand-in for observer effect; hab - categorical effect of habitat class, which was identical to the habitat covariate included in the final model; and trail - the area covered by OHV trails within $100 \mathrm{~m}$ of each survey point center in OHV use areas.

\begin{tabular}{lll}
\hline \hline Covariates & Bayesian P-value & Distance from 0.5 \\
\hline trail & 0.50 & 0.00 \\
hab & 0.49 & 0.01 \\
hab + trail & 0.49 & 0.01 \\
time + hab & 0.49 & 0.01 \\
time + hab + trail & 0.51 & 0.01 \\
time + trail & 0.51 & 0.01 \\
year + hab & 0.51 & 0.01 \\
year + trail & 0.51 & 0.01 \\
none & 0.47 & 0.03 \\
year & 0.47 & 0.03 \\
time + year & 0.47 & 0.04 \\
time + year + hab & 0.54 & 0.04 \\
time & 0.44 & 0.06 \\
year + hab + trail & 0.56 & 0.06 \\
time + year + trail & 0.57 & 0.07 \\
\hline
\end{tabular}




\section{Appendix 8.}

Bayesian p-values for half-normal and negative-exponential formulations of winter and spring community detection models when model included no other detection covariates. Values closer to 0.5 indicate better fit.

\begin{tabular}{ll}
\hline \hline & Bayesian \\
Model & p-value \\
\hline Winter half-normal & 0.00 \\
Winter negative-exponential & 0.07 \\
Spring half-normal & 0.00 \\
Spring negative-exponential & 0.41 \\
\hline
\end{tabular}

